\title{
Comparativo entre preço máximo ao consumidor de medicamentos e preços praticados na internet no Brasil: desalinhamentos e distorções regulatórias
}

\author{
Comparison between maximum consumer prices \\ for medicines and prices practiced on the internet in Brazil: \\ misalignments and regulatory distortions
}

Caroline Miranda Alves de Souza (https://orcid.org/0000-0001-7126-2348) ${ }^{1}$

Julia Paranhos (https://orcid.org/0000-0003-4425-7484) ${ }^{1}$

Lia Hasenclever (https://orcid.org/0000-0003-1384-6323) ${ }^{2}$

${ }^{1}$ Instituto de Economia, Universidade Federal do Rio de Janeiro. Av. Pasteur 250 Palácio Universitário, Campus da Praia Vermelha, 22290-902. Rio de Janeiro RJ Brasil.carol_miranda91@ hotmail.com

${ }^{2}$ Programa de PósGraduação em Planejamento Regional e Gestão de Cidades, Universidade Cândido Mendes. Campos dos Goytacazes RJ Brasil.

\begin{abstract}
Since 2003, the Medicine Market Regulation Chamber (CMED, in portuguese) has been responsible for establishing the maximum consumer prices (MCP) for medicines. The aim of this study is to compare prices practiced on the internet with the MCP and identify the average price difference between them in two segments of existing drugs in Brazil, the reference and the generic ones. Drug prices were collected on websites of pharmacies and drugstores and compared with their respective MCP for the year 2019. The analysis included 68 drugs and 268 commercial presentations of generic and reference drugs related to these drugs. A different pattern was observed for the average price difference in relation to the $M C P$ in each market segment, with most generic drugs tending to show the highest differences and the reference drugs the lowest ones. The problem of price distortion in relation to the MCP pointed out by the literature was confirmed mainly in relation to the generic drug market. It was concluded that a periodic review of the MCP would be important, considering retail prices.
\end{abstract}

Key words Government regulation, Drugs price, Drugs generics
Resumo Desde 2003, a Câmara de Regulação do Mercado de Medicamentos (CMED) é responsável por estabelecer o preço máximo ao consumidor (PMC) para medicamentos. O objetivo deste estudo é comparar preços praticados na internet com o PMC e verificar como se dá a diferença média de preços entre eles no mercado em dois segmentos de medicamentos existentes no Brasil, os de referência e os genéricos. Foi realizada uma coleta de preços de medicamentos em sítios eletrônicos de farmácias e drogarias e os preços coletados foram comparados com os seus respectivos PMCs para o ano de 2019. Foram analisados 68 fármacos e 268 apresentações comerciais de medicamentos genéricos e de referência relativas a esses fármacos. Observou-se um padrão distinto para a diferença média de preços praticados em relação ao PMC em cada segmento de mercado, sendo que, em sua maioria, os genéricos tendiam a praticar as maiores diferenças e os de referência as menores diferenças. O problema da distorção dos preços praticados em relação ao PMC apontados pela literatura foi confirmado principalmente em relação ao mercado de genéricos. Conclui-se que seria importante uma revisão periódica do PMC levando em conta os preços praticados no varejo. Palavras-chave Regulamentação governamental, Preço de medicamento, Medicamentos genéricos 


\section{Introdução}

Em 2003, por meio da implementação da Lei 10.742, criou-se a Câmara de Regulação do Mercado de Medicamentos (CMED) ${ }^{1}$, que passou a estabelecer preços máximos ao consumidor (PMC) para medicamentos, assim como uma série de outros controles ${ }^{2}$. Em termos da literatura econômica, isso significou adotar o modelo de preço-teto para regulação de preços nesse mercado $^{2}$.

As regras para o ajuste e a determinação dos preços dos medicamentos foram estabelecidas por meio do artigo 4 da Lei 10.742/03. Além disso, os reajustes passaram a ter data-base em março. $\mathrm{O}$ ajuste de preços de medicamentos se baseia em um modelo de teto de preços calculado com base: (1) em um índice - o Índice Nacional de Preços ao Consumidor Amplo (IPCA), que é calculado pelo Instituto Brasileiro de Geografia e Estatística (IBGE); (2) em um fator de produtividade - expresso em percentual e que permite repassar aos consumidores ganhos de produtividade das empresas produtoras de medicamentos; e (3) em um fator de ajuste de preços relativos intrassetor - calculado com base no poder de mercado, que é determinado pelo poder de monopólio ou oligopólio, na assimetria de informação, nas barreiras à entrada e outros, e entre setores - calculado com base na variação dos custos dos insumos, desde que tais custos não sejam recuperados pelo cômputo do índice ${ }^{3}$.

$\mathrm{O}$ ajuste de preços de medicamentos tem como referência o mais recente preço do fabricante (PF). Por sua vez, o preço máximo ao consumidor (PMC) é obtido por meio da divisão do PF pelos fatores calculados, levando em conta as cargas tributárias do imposto sobre circulação de mercadorias e serviços (ICMS) praticadas nos estados de destino e a incidência da contribuição para o programa de integração social e o programa de formação do patrimônio do servidor público (PIS/Pasep) e contribuição para o financiamento da seguridade social (COFINS). As unidades de comércio varejista deverão manter à disposição dos consumidores e dos órgãos de defesa do consumidor as listas dos preços de medicamentos atualizadas, contendo $\mathrm{PF}$ e $\mathrm{PMC}^{4}$.

Além da regra para reajuste de preços, a CMED, por meio da Resolução 2, de 2004, passou a ser responsável por controlar os preços de entrada dos medicamentos, conforme regras específicas para cada tipo. Os tipos de medicamentos abordados neste artigo são: medicamentos genéricos e de referência. $\mathrm{O}$ segmento de genéricos foi implementado no Brasil, em 1999, por meio da Lei 9.787, que definiu estes medicamentos como intercambiáveis a um produto de referência, podendo ser produzidos após a expiração ou renúncia da proteção patentária, devendo comprovar a sua eficácia, segurança e qualidade e sendo designados pela sua Denominação Comum Brasileira ou Internacional ${ }^{5}$. Por sua vez, o medicamento de referência é o produto inovador registrado na Agência Nacional de Vigilância Sanitária (Anvisa) e comercializado no país, cuja eficácia, segurança e qualidade foram comprovados, cientificamente, no órgão federal competente, por ocasião do registro ${ }^{6}$. Com a lei dos genéricos, o Brasil passou a ter três segmentos de mercado diferenciados: o de medicamentos de referência, o de genéricos e o de similares, estes últimos não abordados neste estudo por poderem diferir dos medicamentos de referência em relação a algumas características e por serem identificados por nome comercial, diferentemente dos genéricos ${ }^{6}$.

Assim, para os medicamentos analisados neste estudo, a Resolução 2, de 2004, passa a estabelecer que: (1) para os produtos novos (Categoria I), o PF proposto pela empresa não poderá ser superior ao menor PF praticado para o mesmo produto nos países relacionados (Austrália, Canadá, Espanha, EUA, França, Grécia, Itália, Nova Zelândia, Portugal e o PF praticado no país de origem do produto), agregando-se os impostos incidentes, conforme o caso; (2) para a Categoria II, produtos novos que não se enquadrem na definição anterior, o PF será definido tendo como base o custo de tratamento com os medicamentos utilizados para a mesma indicação terapêutica, não podendo ser superior ao menor preço praticado dentre os países relacionados; e (3) para o genérico (Categoria VI), o PF não poderá ser superior a $65 \%$ do preço do medicamento de referência correspondente ${ }^{7}$.

Como apontam Dias et al. ${ }^{8}$, o atual modelo de reajuste de preços tem utilizado PMCs descolados da realidade, aumentando a assimetria de informação e possibilitando futuros aumentos abusivos. Modelos regulatórios baseados em teto de preços, como o utilizado no Brasil, pressupõem realinhamentos periódicos dos preços aos valores de mercado a cada dois até, no máximo, cinco anos. No Brasil, este modelo permanece há 16 anos em vigor, sem qualquer realinhamento, com consequentes distorções acumuladas entre PMC e preços praticados ${ }^{8}$. O fato de não se realizar avaliações periódicas dos preços praticados no mercado, ajustando o PMC para algo mais próximo da realidade do mercado parece ser um 
problema bastante relevante e com implicações para a eficácia da regulação e para o bem-estar dos consumidores.

Além disso, Dias et al. ${ }^{8}$ consideram várias outras possibilidades de que a regulação acima descrita traga problemas, por exemplo, no que diz respeito a determinação da produtividade. Ademais, para cada medicamento genérico que entra no mercado é estabelecido um novo PMC, o que torna mais complexa a fiscalização dos preços praticados no mercado. Miziara e Coutinho ${ }^{9}$ já realizaram uma breve análise do distanciamento entre o PMC e os preços praticados, porém focaram em um único estado brasileiro (São Paulo) com preços coletados nas lojas físicas entre os anos de 2009 e 2012.

Neste artigo, todavia, é utilizada uma pesquisa de preços de medicamentos em sítios eletrônicos das maiores redes de farmácias e drogarias do Brasil, sendo algumas dessas redes regionais e outras que atuam em todo o país. Apesar da diversidade de atuação dessas redes, os preços coletados correspondem ao padrão dos sítios eletrônicos das mesmas, não sendo possível afirmar que são idênticos e abrangem todas as regiões. Além disso, esse artigo se diferencia do estudo realizado por Miziara e Coutinho 9 por discutir como a determinação do PMC pode afetar de formas distintas dois segmentos de medicamentos existentes no Brasil, quais sejam: os medicamentos de referência e genéricos.

As assimetrias de informação causadas pelo descolamento dos preços praticados no mercado em relação ao PMC estabelecido apontam para a necessidade de avaliação periódica dos preços de mercado dos medicamentos no Brasil e suas implicações para o bem-estar dos consumidores. Tais resultados podem ser de extrema relevância para avaliação da CMED sobre a regulação de preço de medicamentos.

O objetivo do artigo é comparar preços praticados na internet pelo varejo farmacêutico brasileiro com o PMC estabelecido pela CMED e gerar novas evidências sobre a regulação de preços de medicamentos no Brasil. Propõe-se a responder as seguintes perguntas de pesquisa: Há algum padrão para o distanciamento entre preços praticados e PMC no mercado brasileiro de medicamentos genéricos e de referência?

\section{Metodologia}

Algumas instituições privadas dispõem de bases de dados sobre preços praticados no varejo, todavia o acesso é restrito ou apenas podem ser disponibilizados sob certas circunstâncias (por exemplo, IQVIA, disponível em $h t t p s: / / w w w . i q-$ via.com/). Tendo em vista a não disponibilidade de uma base de dados pública para os objetivos desse estudo, foi elaborado um método de busca em sítios eletrônicos para o levantamento de preços de medicamentos, descrita a seguir.

A lista de farmácias e drogarias disponível no sítio eletrônico da Associação Brasileira de Redes de Farmácias e Drogarias (ABRAFARMA) ${ }^{10}$, a qual congrega as maiores redes de farmácias e drogarias no Brasil, foi a base para a coleta de dados na internet. Desta lista, foram selecionadas as farmácias e drogarias que possuíam sítios eletrônicos e que permitiam a coleta de informações. As farmácias e drogarias selecionadas, assim como outras informações, são apresentadas no Quadro 1.

Quanto à localização geográfica das farmácias e drogarias, observa-se que: (1) a Droga Raia atua em toda a Região Sul e nos estados de São Paulo, Rio de Janeiro, Minas Gerais, Goiás e Mato Grosso do Sul ${ }^{11}$; (2) a Drogasil nas Regiões Sul, Sudeste e Centro-Oeste e nos estados da Bahia, Pernambuco, Sergipe, Alagoas, Paraíba e Rio Grande do Norte ${ }^{12}$; (3) as Drogarias Pacheco nos estados do Rio de Janeiro, Minas Gerais, Espírito Santo, Goiás, Paraná e Distrito Federal ${ }^{13}$; (4) a Drogaria São Paulo nos estados de São Paulo, Minas Gerais, Rio de Janeiro, Bahia, Pernambuco, Paraíba e Alagoas ${ }^{14}$; (5) a Panvel em toda a Região Sul e no estado de São Paulo ${ }^{15}$; (6) a Farmácia Pague Menos em todos os estados e no Distrito Federal $^{16}$; (7) a Drogaria Araujo em Belo Horizonte e algumas cidades de Minas Gerais ${ }^{17}$; (8) as Farmácias Nissei nos estados de Paraná, São Paulo e Santa Catarina ${ }^{18}$; (9) a Drogaria Venancio exclusivamente no estado do Rio de Janeiro ${ }^{19}$; e (10) a Rede Drogal no interior do estado de São Paulo ${ }^{20}$.

A coleta de preços ocorreu por meio de programação desenvolvida pelos autores no Visual Basic for Applications (VBA) do Microsoft Office Excel. Ela foi construída para extrair diretamente dos sítios eletrônicos das farmácias e drogarias os dados de descrição do medicamento, nome de marca e preço. Esses dados foram organizados em um banco de dados no Excel que serviram de base para este estudo. A coleta na internet foi realizada entre os dias 11 e 16 de setembro de 2019.

A escolha dos fármacos, esquematicamente representada na Figura 1, se deu por conveniência. As etapas consideradas foram: (1) seleção das subclasses terapêuticas que eram idênticas em dois períodos de tempo, a saber 2001 e 2016 
Quadro 1. Lista de farmácias e drogarias $(\mathrm{n}=10)$.

\begin{tabular}{|l|l|l|}
\hline \multicolumn{1}{|c|}{$\begin{array}{c}\text { Ranking } \\
\text { Faturamento 2018 }\end{array}$} & \multicolumn{1}{|c|}{ Farmácias/Drogarias } & \multicolumn{1}{c|}{ Sites } \\
\hline \multirow{2}{*}{1} & Drogasil & https://www.drogasil.com.br/ \\
\cline { 2 - 3 } & Raia & https://www.drogaraia.com.br/ \\
\hline 2 & São Paulo & https://www.drogariasaopaulo.com.br/ \\
\cline { 2 - 3 } & Pacheco & https://www.drogariaspacheco.com.br/ \\
\hline 3 & Pague Menos & https://www.paguemenos.com.br/ \\
\hline 5 & Panvel & https://www.panvel.com/panvel/main.do \\
\hline 7 & Araujo & https://www.araujo.com.br/ \\
\hline 8 & Nissei & https://www.farmaciasnissei.com.br/ \\
\hline 9 & Venancio & https://www.drogariavenancio.com.br/ \\
\hline 12 & Drogal & https://www.drogal.com.br/ \\
\hline
\end{tabular}

Fonte: Elaboração própria com base em ABRAFARMA ${ }^{10}$.

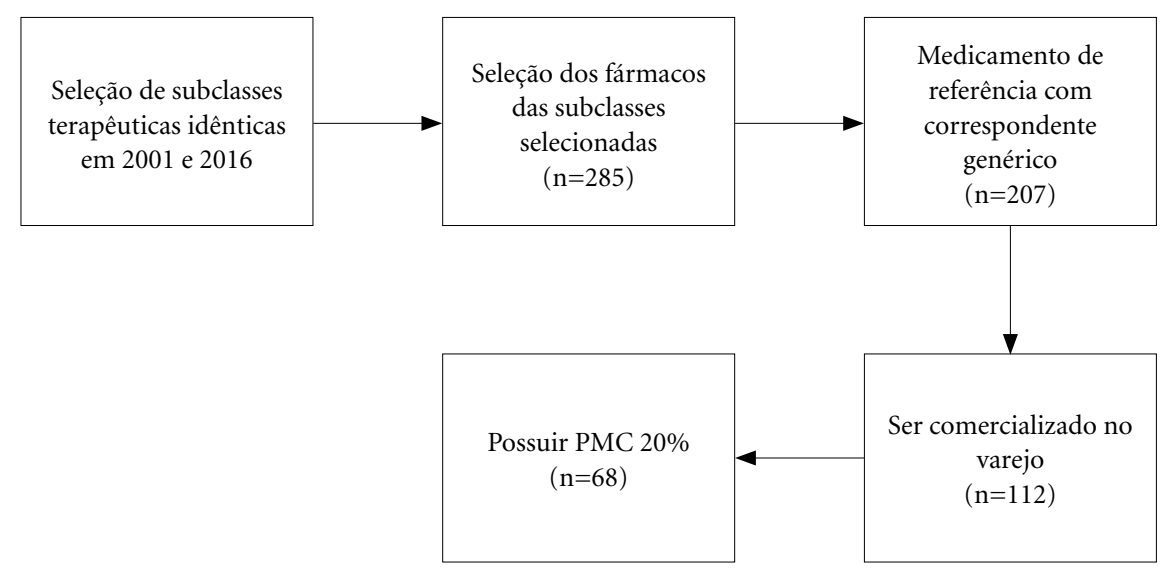

Figura 1. Etapas para seleção dos fármacos analisados.

Fonte: Elaboração própria.

(para mais detalhes ver Souza ${ }^{21}$ ); (2) pesquisa dos fármacos das subclasses terapêuticas selecionadas; (3) verificação de quais medicamentos de referência possuíam correspondentes genéricos; (4) coleta de preços dos medicamentos que eram comercializados no varejo farmacêutico; e (5) exclusão daqueles que não possuíam PMC 20\% estabelecido pela CMED.

Em relação à última etapa, cabe ressaltar que alguns medicamentos não possuem PMC por serem: (1) medicamentos de preços liberados (Resolução CMED no 02/2019); ou (2) isentos de $\mathrm{ICMS}^{22}$. Além disso, o ICMS varia de acordo com o estado de comercialização e existem seis faixas, às quais variam entre $0 \%$ e $20 \%$. Para a análise dos dados foram considerados apenas os valores extremos de ICMS de 20\% - denominados a partir daqui como PMC (20\%). Essa é uma limitação da pesquisa já que a variabilidade de ICMS por estados não foi avaliada.

A coleta de preços foi feita apenas para os medicamentos genéricos e de referência. Os genéricos são comercializados pelo nome do seu princípio ativo, ou seja, pelo nome do fármaco, facilitando a sua identificação com o medicamento de referência aos quais são intercambiáveis, conforme a legislação. A razão para não pesquisar os medicamentos similares é que, apesar da exigência de intercambialidade existir desde 2003, ela não é imediatamente evidente por ser o medicamento comercializado por sua marca e a garantia da intercambialidade só constar da 
bula do medicamento ${ }^{23}$. Além disso, há atraso no cumprimento do cronograma de exigências da Anvisa para definir a intercambialidade dos medicamentos similares. Por essas razões, sua inclusão na comparabilidade de preços exigiria procedimentos de pesquisa adicionais.

Assim, foram pesquisados os correspondentes genéricos dos fármacos de referência nos registros de genéricos na Anvisa com base na lista de registro de medicamentos genéricos de 05 de agosto de $2019^{24}$. Para verificar se o medicamento era comercializado no varejo, foi feita uma pesquisa sobre os preços disponíveis nos sítios eletrônicos selecionados. O Quadro 2 mostra o conjunto final da amostra de conveniência composta de 68 fármacos e os nomes de marca dos medicamentos de referência. A pesquisa de preços foi obtida para 268 apresentações comerciais de medicamentos genéricos e de referência para análise (todas as apresentações comerciais analisadas encontram-se no Quadro 3).

Para contrapor os preços coletados na internet, foi utilizada a lista de preços máximos de medicamentos por princípio ativo da $\mathrm{CMED}^{22}$, doravante indicada como Tabela CMED, atualizada em 01 de julho de 2019. O PMC é o preço máximo que pode ser praticado pelo comércio varejista de medicamentos e contempla tanto a margem de comercialização como os impostos inerentes a esses tipos de comércio ${ }^{22}$.

Os procedimentos para o cálculo das diferenças de preços praticados e o PMC exigiram alguns cuidados. Como para cada medicamento genérico havia um PMC estabelecido por empresa, foram feitas correspondências entre o medicamento com o preço coletado no varejo e o seu respectivo PMC (20\%), os quais deveriam ter as mesmas características (mesmo fármaco, apresentação, forma farmacêutica e produtor). Sendo assim, foi calculada a média dos PMCs (20\%) informados pela Tabela CMED. Para os medicamentos de referência, por haver um único PMC, não foi preciso calcular uma média para o PMC $(20 \%)$. Ao coletar dados em diferentes farmácias foram obtidos vários e diferentes preços para cada apresentação comercial do medicamento coletado na internet. De forma a estabelecer um ponto referencial para a comparação com o PMC (20\%) foram calculadas as médias dos preços praticados por apresentação, tanto dos medicamentos genéricos quanto dos de referência.

Os resultados foram divididos em duas faixas de análise de acordo com os padrões mais frequentes de diferença média percentuais, a saber: (1) faixa superior, com diferença média percen- tual de $-60 \%$, onde se concentrava as 12 maiores diferenças de preços; e (2) faixa inferior, com diferença média percentual de $-10 \%$, onde se concentrava as nove menores diferenças de preços. Além disso, os dados gerais são apresentados com diferença média percentual de $-40 \%$, que serviu como um divisor para o maior número de medicamentos, seja de genérico (superior a $40 \%$ ) ou de referência (inferior a 40\%).

\section{Resultados}

Os resultados mostram um comportamento distinto dos preços praticados pelos medicamentos de referência e os genéricos em relação ao PMC. Das 134 apresentações comerciais de medicamentos de referência, apenas 13 praticavam preços médios que estavam mais de $40 \%$ abaixo do PMC (20\%). Enquanto das 134 apresentações comerciais de genéricos, 96 possuíam preços médios praticados que estavam mais de $40 \%$ abaixo do PMC (20\%) médio. Assim, foi possível observar um padrão para o distanciamento de preços decorrentes do segmento de mercado, em que medicamentos genéricos, em sua maioria $(72 \%)$, tendiam a praticar diferenças médias percentuais de preços que estavam mais de $40 \%$ abaixo do PMC e a maioria dos medicamentos de referência $(88 \%)$ tendia a praticar diferenças médias percentuais que estavam menos de $40 \%$ abaixo do PMC.

Esse resultado parece indicar uma dinâmica de mercado que induz os genéricos a se distanciarem bastante do PMC que lhes é possível praticar, devido à concorrência entre eles, e que, no segmento de referência, o preço praticado dos medicamentos é mais próximo ao seu respectivo PMC, mostrando a força da marca mesmo frente a concorrência dos genéricos.

Foi possível ainda notar que as diferenças médias percentuais entre os preços praticados e o PMC de forma geral variavam bastante, incluindo medicamentos que praticavam diferenças médias percentuais de preços de $-83 \%$ em relação ao PMC e medicamentos que possuíam preços praticados superiores (24\%) aos seus PMCs.

Como mostra a Tabela 1, dentre os medicamentos com preços praticados médios que estavam mais de $60 \%$ abaixo do PMC (20\%) médio, apenas dois eram de referência: "Cymbalta" e "Prozac", todos os demais eram genéricos. Deste modo, observou-se um predomínio de genéricos praticando preços mais afastados do PMC em relação aos medicamentos de referência. Ainda em 
Quadro 2. Lista de fármacos ( $\mathrm{n}=68)$.

\begin{tabular}{|c|c|c|c|}
\hline Denominação Genérica & Referência & Denominação Genérica & Referência \\
\hline Acetato de ciproterona + etinilestradiol & Diane 35 & Dicloridrato de cetirizina & Zyrtec \\
\hline Aciclovir & Zovirax & Dicloridrato de levocetirizina & Zyxem \\
\hline Alopurinol & Zyloric & Dicloridrato de pramipexol & Sifrol \\
\hline Axetilcefuroxima & Zinnat & Divalproato de sodio & Depakote \\
\hline Bimatoprosta & Lumigan & $\begin{array}{l}\text { Enantato de noretisterona + valerato } \\
\text { de estradiol }\end{array}$ & Mesigyna \\
\hline Bissulfato de clopidogrel & Plavix & Fenobarbital & Gardenal \\
\hline Carbamazepina & Tegretol & Furosemida & Lasix \\
\hline Carbonato de lítio & Carbolitium & Gabapentina & Neurontin \\
\hline Cefalexina & Keflex & Hemitartarato de zolpidem & Stilnox \\
\hline Ceftriaxona sódica & Rocefin & Indapamida & Natrilix SR \\
\hline Cetoconazol & Nizoral & Lamotrigina & Lamictal \\
\hline Ciclopirox olamina & Loprox & Latanoprosta & Xalatan \\
\hline Cilostazol & Cebralat & Latanoprosta + maleato de timolol & Xalacom \\
\hline Clonazepam & Rivotril & Levotiroxina sódica & Puran T4 \\
\hline Cloridrato de amilorida + hidroclorotiazida & Moduretic & Loratadina & Claritin \\
\hline Cloridrato de clindamicina & Dalacin C & Maleato de dexclorfeniramina & Polaramine \\
\hline Cloridrato de clomipramina & Anafranil & $\begin{array}{l}\text { Maleato de dexclorfeniramina }+ \\
\text { betametasona }\end{array}$ & Celestamine \\
\hline $\begin{array}{l}\text { Cloridrato de dorzolamida }+ \text { maleato de } \\
\text { timolol }\end{array}$ & Cosopt & Maleato de midazolam & Dormonid \\
\hline Cloridrato de duloxetina & Cymbalta & Maleato de timolol & Timoptol \\
\hline Cloridrato de fexofenadina & Allegra & Metronidazol & Flagyl \\
\hline Cloridrato de fluoxetina & Prozac & Mirtazapina & $\begin{array}{l}\text { Remeron } \\
\text { Soltab }\end{array}$ \\
\hline Cloridrato de naratriptana & Naramig & Nistatina + óxido de zinco & Dermodex \\
\hline Cloridrato de nortriptilina & Pamelor & Nitrato de fenticonazol & Fentizol \\
\hline Cloridrato de propafenona & Ritmonorm & Nitrazepam & Sonebon \\
\hline Cloridrato de sertralina & Zoloft & Olanzapina & Zyprexa \\
\hline Cloridrato de tansulosina & Secotex & Oxalato de escitalopram & Lexapro \\
\hline Cloridrato de tramadol & Tramal & Oxcarbazepina & Trileptal \\
\hline Cloridrato de trazodona & Donaren & Paracetamol + fosfato de codeína & Tylex \\
\hline Cloridrato de valaciclovir & Valtrex & Pregabalina & Lyrica \\
\hline Cloridrato de venlafaxina & Efexor XR & Succinato de sumatriptana & Imigran \\
\hline Colchicina & Colchis & Sulfadiazina de prata & Dermazine \\
\hline Desloratadina & Desalex & Sulfato de neomicina + bacitracina & Nebacetin \\
\hline Desogestrel & Cerazette & Tartarato de brimonidina & Alphagan \\
\hline Diazepam & Valium & Topiramato & Topamax \\
\hline
\end{tabular}

Fonte: Elaboração própria.

relação a Tabela 1, é possível notar que, entre os medicamentos com preço médio praticado que estavam menos de 10\% abaixo do PMC (20\%) médio, apenas o "Divalproato de Sódio" era um medicamento genérico, todos os demais eram medicamentos de referência.

$\mathrm{Na}$ análise dos dados foi ainda identificada a existência de medicamentos que possuíam preços praticados superiores aos seus respectivos PMCs (20\%), quais sejam: o medicamento "Cosopt" de concentração " $2 \% / 0,5 \%$ ", que tinha maior preço praticado encontrado na coleta de $\mathrm{R} \$ 134,36 \mathrm{e}$ respectivo PMC (20\%) de $\mathrm{R} \$ 131,43$; e, o medicamento "Lyrica" de concentração "75mg”, com maior preço praticado encontrado na coleta de R\$ 227,70 e respectivo PMC (20\%) de R\$ 152,19. Nestes dois casos, a comercialização estava infringindo a regulação que determina o preço máximo que pode ser praticado no mercado para os medicamentos em questão. 
Quadro 3. Dados analisados ( $\mathrm{n}=268)$.

\begin{tabular}{|c|c|c|c|c|}
\hline Medicamento (genérico; referência) & $\begin{array}{c}\text { Forma } \\
\text { farmacêutica } \\
\text { (quantidade) }\end{array}$ & $\begin{array}{l}\text { Preço médio } \\
\text { praticado } \\
\text { (genérico; } \\
\text { referência) } \\
\text { (A) }\end{array}$ & \begin{tabular}{|} 
PMC médio \\
$(20 \%)$ \\
(genérico; \\
referência) \\
(B)
\end{tabular} & 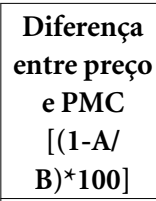 \\
\hline $\begin{array}{l}\text { Acetato de Ciproterona } 2 \mathrm{mg}+\text { Etinilestradiol } \\
0,035 \mathrm{mg}\end{array}$ & \multirow[t]{2}{*}{$\begin{array}{l}21 \text { Comprimidos } \\
\text { Revestidos }\end{array}$} & $\mathrm{R} \$ 10,45$ & $\mathrm{R} \$ 19,69$ & $-47 \%$ \\
\hline Diane 35 & & $\mathrm{R} \$ 24,01$ & $\mathrm{R} \$ 30,25$ & $-21 \%$ \\
\hline $\begin{array}{l}\text { Acetato de Ciproterona } 2 \mathrm{mg}+\text { Etinilestradiol } \\
0,035 \mathrm{mg}\end{array}$ & \multirow[t]{2}{*}{$\begin{array}{l}63 \text { Comprimidos } \\
\text { Revestidos }\end{array}$} & $\mathrm{R} \$ 22,49$ & $\mathrm{R} \$ 41,89$ & $-46 \%$ \\
\hline Diane 35 & & $\mathrm{R} \$ 48,33$ & $\mathrm{R} \$ 64,48$ & $-25 \%$ \\
\hline Aciclovir $200 \mathrm{mg}$ & \multirow[t]{2}{*}{25 Comprimidos } & $\mathrm{R} \$ 45,04$ & $\mathrm{R} \$ 122,36$ & $-63 \%$ \\
\hline Zovirax 200mg & & $\mathrm{R} \$ 251,13$ & $\mathrm{R} \$ 304,34$ & $-17 \%$ \\
\hline Aciclovir $50 \mathrm{mg} / \mathrm{g}$ & \multirow{2}{*}{$\begin{array}{l}\text { 10g Creme } \\
\text { Dermatológico }\end{array}$} & $\mathrm{R} \$ 13,29$ & $\mathrm{R} \$ 26,34$ & $-50 \%$ \\
\hline Zovirax 50mg & & $\mathrm{R} \$ 42,68$ & $\mathrm{R} \$ 51,43$ & $-17 \%$ \\
\hline Alopurinol 100mg & \multirow[t]{2}{*}{30 Comprimidos } & $\mathrm{R} \$ 6,43$ & $\mathrm{R} \$ 10,79$ & $-40 \%$ \\
\hline Zyloric 100mg & & $\mathrm{R} \$ 14,29$ & $\mathrm{R} \$ 16,88$ & $-15 \%$ \\
\hline Alopurinol 300mg & \multirow[t]{2}{*}{30 Comprimidos } & $\mathrm{R} \$ 16,23$ & $\mathrm{R} \$ 31,20$ & $-48 \%$ \\
\hline Zyloric 300mg & & $\mathrm{R} \$ 40,37$ & $\mathrm{R} \$ 49,84$ & $-19 \%$ \\
\hline Axetilcefuroxima $250 \mathrm{mg}$ & \multirow{2}{*}{$\begin{array}{l}10 \text { Comprimidos } \\
\text { Revestidos }\end{array}$} & $\mathrm{R} \$ 41,09$ & $\mathrm{R} \$ 78,55$ & $-48 \%$ \\
\hline Zinnat $250 \mathrm{mg}$ & & $\mathrm{R} \$ 124,49$ & $\mathrm{R} \$ 135,20$ & $-8 \%$ \\
\hline Bimatoprosta $0,3 \mathrm{mg} / \mathrm{ml}$ & \multirow{2}{*}{$\begin{array}{l}\text { 3ml Solução } \\
\text { Oftálmica }\end{array}$} & $\mathrm{R} \$ 52,46$ & $\mathrm{R} \$ 95,55$ & $-45 \%$ \\
\hline Lumigan $0,3 \mathrm{mg} / \mathrm{ml}$ & & $\mathrm{R} \$ 116,88$ & $\mathrm{R} \$ 146,99$ & $-20 \%$ \\
\hline Bimatoprosta $0,3 \mathrm{mg} / \mathrm{ml}$ & \multirow{2}{*}{$\begin{array}{l}5 \mathrm{ml} \text { Solução } \\
\text { oftálmica }\end{array}$} & $\mathrm{R} \$ 82,69$ & $\mathrm{R} \$ 143,33$ & $-42 \%$ \\
\hline Lumigan $0,3 \mathrm{mg} / \mathrm{ml}$ & & $\mathrm{R} \$ 171,99$ & $\mathrm{R} \$ 220,51$ & $-22 \%$ \\
\hline Bissulfato de Clopidogrel 75mg & \multirow{2}{*}{$\begin{array}{l}28 \text { Comprimidos } \\
\text { Revestidos }\end{array}$} & $\mathrm{R} \$ 42,13$ & $\mathrm{R} \$ 149,56$ & $-72 \%$ \\
\hline Plavix 75mg & & $\mathrm{R} \$ 223,40$ & $\mathrm{R} \$ 317,31$ & $-30 \%$ \\
\hline Carbamazepina 200mg & \multirow[t]{2}{*}{20 Comprimidos } & $\mathrm{R} \$ 6,35$ & $\mathrm{R} \$ 10,30$ & $-38 \%$ \\
\hline Tegretol 200mg & & $\mathrm{R} \$ 19,76$ & $\mathrm{R} \$ 23,72$ & $-17 \%$ \\
\hline Carbamazepina 400mg & \multirow[t]{2}{*}{20 Comprimidos } & $\mathrm{R} \$ 15,49$ & $\mathrm{R} \$ 21,84$ & $-29 \%$ \\
\hline Tegretol 400mg & & $\mathrm{R} \$ 41,52$ & $\mathrm{R} \$ 47,18$ & $-12 \%$ \\
\hline Carbamazepina $20 \mathrm{mg} / \mathrm{ml}$ & \multirow{2}{*}{$\begin{array}{l}\text { 100ml Solução } \\
\text { Oral }\end{array}$} & $\mathrm{R} \$ 10,34$ & $\mathrm{R} \$ 16,69$ & $-38 \%$ \\
\hline Tegretol $20 \mathrm{mg} / \mathrm{ml}$ & & $\mathrm{R} \$ 23,74$ & $\mathrm{R} \$ 25,74$ & $-8 \%$ \\
\hline Carbonato de Lítio 300mg & \multirow{2}{*}{$\begin{array}{l}50 \text { Comprimidos } \\
\text { Revestidos }\end{array}$} & $\mathrm{R} \$ 20,59$ & $\mathrm{R} \$ 25,45$ & $-19 \%$ \\
\hline Carbolitium 300mg & & $\mathrm{R} \$ 34,06$ & $\mathrm{R} \$ 40,62$ & $-16 \%$ \\
\hline Cefalexina $250 \mathrm{mg} / 5 \mathrm{ml}$ & \multirow[t]{2}{*}{ 100ml Suspensão } & $\mathrm{R} \$ 26,36$ & $\mathrm{R} \$ 46,38$ & $-43 \%$ \\
\hline Keflex $250 \mathrm{mg} / 5 \mathrm{ml}$ & & $\mathrm{R} \$ 86,49$ & $\mathrm{R} \$ 107,03$ & $-19 \%$ \\
\hline Ceftriaxona Sódica 1g & \multirow[t]{2}{*}{1 Ampola } & $\mathrm{R} \$ 18,72$ & - & - \\
\hline Rocefin $1 \mathrm{~g}$ & & $\mathrm{R} \$ 177,25$ & - & - \\
\hline Cetoconazol 20mg/g & \multirow[t]{2}{*}{$30 \mathrm{~g}$ Creme } & $\mathrm{R} \$ 13,39$ & $\mathrm{R} \$ 21,84$ & $-39 \%$ \\
\hline Nizoral Tópico 20mg & & $\mathrm{R} \$ 35,90$ & $\mathrm{R} \$ 42,54$ & $-16 \%$ \\
\hline Ciclopirox Olamina 10mg/g & \multirow{2}{*}{$\begin{array}{l}\text { 20g Creme } \\
\text { Dermatológico }\end{array}$} & $\mathrm{R} \$ 16,27$ & $\mathrm{R} \$ 29,94$ & $-46 \%$ \\
\hline Loprox $10 \mathrm{mg} / \mathrm{g}$ & & $\mathrm{R} \$ 42,71$ & $\mathrm{R} \$ 47,72$ & $-11 \%$ \\
\hline Cilostazol 100mg & \multirow[t]{2}{*}{30 Comprimidos } & $\mathrm{R} \$ 28,00$ & $\mathrm{R} \$ 61,72$ & $-55 \%$ \\
\hline Cebralat 100mg & & $\mathrm{R} \$ 46,39$ & $\mathrm{R} \$ 56,69$ & $-18 \%$ \\
\hline Cilostazol 100mg & \multirow[t]{2}{*}{60 Comprimidos } & $\mathrm{R} \$ 38,51$ & $\mathrm{R} \$ 75,21$ & $-49 \%$ \\
\hline Cebralat 100mg & & $\mathrm{R} \$ 57,34$ & $\mathrm{R} \$ 69,33$ & $-17 \%$ \\
\hline Cilostazol 50mg & \multirow[t]{2}{*}{30 Comprimidos } & $\mathrm{R} \$ 16,36$ & $\mathrm{R} \$ 30,37$ & $-46 \%$ \\
\hline Cebralat 50mg & & $\mathrm{R} \$ 22,54$ & $\mathrm{R} \$ 28,73$ & $-22 \%$ \\
\hline Cilostazol 50mg & \multirow[t]{2}{*}{60 Comprimidos } & $\mathrm{R} \$ 19,75$ & $\mathrm{R} \$ 37,62$ & $-47 \%$ \\
\hline Cebralat 50mg & & $\mathrm{R} \$ 29,42$ & $\mathrm{R} \$ 34,55$ & $-15 \%$ \\
\hline Clonazepam $0,5 \mathrm{mg}$ & \multirow[t]{2}{*}{30 Comprimidos } & $\mathrm{R} \$ 5,72$ & $\mathrm{R} \$ 9,07$ & $-37 \%$ \\
\hline Rivotril 0,5mg & & $\mathrm{R} \$ 11,97$ & $\mathrm{R} \$ 14,06$ & $-15 \%$ \\
\hline
\end{tabular}


Quadro 3. Dados analisados $(\mathrm{n}=268)$.

\begin{tabular}{|c|c|c|c|c|}
\hline Medicamento (genérico; referência) & $\begin{array}{c}\text { Forma } \\
\text { farmacêutica } \\
\text { (quantidade) }\end{array}$ & $\begin{array}{l}\text { Preço médio } \\
\text { praticado } \\
\text { (genérico; } \\
\text { referência) } \\
\text { (A) }\end{array}$ & \begin{tabular}{|} 
PMC médio \\
$(20 \%)$ \\
(genérico; \\
referência) \\
(B)
\end{tabular} & 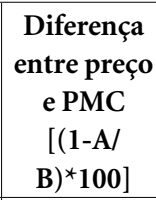 \\
\hline Clonazepam 2mg & \multirow[t]{2}{*}{30 Comprimidos } & $\mathrm{R} \$ 10,20$ & $\mathrm{R} \$ 15,93$ & $-36 \%$ \\
\hline Rivotril 2mg & & $\mathrm{R} \$ 20,59$ & $\mathrm{R} \$ 24,62$ & $-16 \%$ \\
\hline Clonazepam $2,5 \mathrm{mg} / \mathrm{ml}$ & \multirow[t]{2}{*}{ 20ml Solução Oral } & $\mathrm{R} \$ 8,14$ & $\mathrm{R} \$ 13,10$ & $-38 \%$ \\
\hline Rivotril $2,5 \mathrm{mg} / \mathrm{ml}$ & & $\mathrm{R} \$ 18,79$ & $\mathrm{R} \$ 22,17$ & $-15 \%$ \\
\hline $\begin{array}{l}\text { Cloridrato de Amilorida 2,5mg + Hidroclorotiazida } \\
25 \mathrm{mg}\end{array}$ & \multirow[t]{2}{*}{30 Comprimidos } & $\mathrm{R} \$ 6,55$ & $\mathrm{R} \$ 10,71$ & $-39 \%$ \\
\hline Moduretic $25 \mathrm{mg}+2,5 \mathrm{mg}$ & & $\mathrm{R} \$ 10,45$ & $\mathrm{R} \$ 14,14$ & $-26 \%$ \\
\hline $\begin{array}{l}\text { Cloridrato de Amilorida 5mg + Hidroclorotiazida } \\
\text { 50mg }\end{array}$ & \multirow[t]{2}{*}{30 Comprimidos } & $\mathrm{R} \$ 11,23$ & $\mathrm{R} \$ 17,89$ & $-37 \%$ \\
\hline Moduretic 50/5mg & & $\mathrm{R} \$ 17,95$ & $\mathrm{R} \$ 23,60$ & $-24 \%$ \\
\hline Cloridrato de Clindamicina 300mg & \multirow[t]{2}{*}{16 Cápsulas } & $\mathrm{R} \$ 40,31$ & $\mathrm{R} \$ 80,23$ & $-50 \%$ \\
\hline Dalacin C 300mg & & $\mathrm{R} \$ 112,16$ & $\mathrm{R} \$ 133,45$ & $-16 \%$ \\
\hline Cloridrato de Clomipramina 25mg & \multirow{2}{*}{$\begin{array}{l}20 \text { Comprimidos } \\
\text { Revestidos }\end{array}$} & $\mathrm{R} \$ 16,49$ & $\mathrm{R} \$ 28,11$ & $-41 \%$ \\
\hline Anafranil $25 \mathrm{mg}$ & & $\mathrm{R} \$ 34,99$ & $\mathrm{R} \$ 43,30$ & $-19 \%$ \\
\hline $\begin{array}{l}\text { Cloridrato de Dorzolamida 2\% + Maleato de } \\
\text { Timolol 0,5\% }\end{array}$ & \multirow[t]{2}{*}{$\begin{array}{l}5 \mathrm{ml} \text { Solução } \\
\text { Oftálmica }\end{array}$} & $\mathrm{R} \$ 46,82$ & $\mathrm{R} \$ 86,85$ & $-46 \%$ \\
\hline Cosopt $2 \% / 0,5 \%$ & & $\mathrm{R} \$ 120,96$ & $\mathrm{R} \$ 131,43$ & $-8 \%$ \\
\hline Cloridrato de Duloxetina 30mg & \multirow{2}{*}{$\begin{array}{l}30 \text { Cápsulas Duras } \\
\text { de Liberação } \\
\text { Retardada }\end{array}$} & $\mathrm{R} \$ 63,06$ & $\mathrm{R} \$ 158,65$ & $-60 \%$ \\
\hline Cymbalta 30mg & & $\mathrm{R} \$ 72,38$ & $\mathrm{R} \$ 244,04$ & $-70 \%$ \\
\hline Cloridrato de Duloxetina 60mg & \multirow{2}{*}{$\begin{array}{l}30 \text { Cápsulas Duras } \\
\text { de Liberação } \\
\text { Retardada }\end{array}$} & $\mathrm{R} \$ 136,95$ & $\mathrm{R} \$ 317,28$ & $-57 \%$ \\
\hline Cymbalta 60mg & & $\mathrm{R} \$ 137,04$ & $\mathrm{R} \$ 488,10$ & $-72 \%$ \\
\hline Cloridrato de Fexofenadina $60 \mathrm{mg}$ & \multirow{2}{*}{$\begin{array}{l}10 \text { Comprimidos } \\
\text { Revestidos }\end{array}$} & $\mathrm{R} \$ 16,01$ & $\mathrm{R} \$ 20,94$ & $-24 \%$ \\
\hline Allegra 60mg & & $\mathrm{R} \$ 25,95$ & $\mathrm{R} \$ 32,24$ & $-20 \%$ \\
\hline Cloridrato de Fexofenadina 120mg & \multirow{2}{*}{$\begin{array}{l}10 \text { Comprimidos } \\
\text { Revestidos }\end{array}$} & $\mathrm{R} \$ 22,86$ & $\mathrm{R} \$ 41,21$ & $-45 \%$ \\
\hline Allegra $120 \mathrm{mg}$ & & $\mathrm{R} \$ 49,09$ & $\mathrm{R} \$ 63,48$ & $-23 \%$ \\
\hline Cloridrato de Fexofenadina 180mg & \multirow{2}{*}{$\begin{array}{l}10 \text { Comprimidos } \\
\text { Revestidos }\end{array}$} & $\mathrm{R} \$ 33,62$ & $\mathrm{R} \$ 61,86$ & $-46 \%$ \\
\hline Allegra $180 \mathrm{mg}$ & & $\mathrm{R} \$ 82,24$ & $\mathrm{R} \$ 96,93$ & $-15 \%$ \\
\hline Cloridrato de Fluoxetina 20mg & \multirow{2}{*}{30 Cápsulas Dura } & $\mathrm{R} \$ 20,66$ & $\mathrm{R} \$ 59,07$ & $-65 \%$ \\
\hline Prozac 20mg & & $\mathrm{R} \$ 104,24$ & $\mathrm{R} \$ 275,16$ & $-62 \%$ \\
\hline Cloridrato de Naratriptana $2,5 \mathrm{mg}$ & \multirow{2}{*}{$\begin{array}{l}4 \text { Comprimidos } \\
\text { Revestidos }\end{array}$} & $\mathrm{R} \$ 8,96$ & $\mathrm{R} \$ 13,34$ & $-33 \%$ \\
\hline Naramig 2,5mg & & $\mathrm{R} \$ 15,99$ & $\mathrm{R} \$ 20,50$ & $-22 \%$ \\
\hline Cloridrato de Nortriptilina 25mg & \multirow{2}{*}{30 Cápsulas } & $\mathrm{R} \$ 16,75$ & $\mathrm{R} \$ 29,96$ & $-44 \%$ \\
\hline Pamelor 25mg & & $\mathrm{R} \$ 36,37$ & $\mathrm{R} \$ 46,05$ & $-21 \%$ \\
\hline Cloridrato de Nortriptilina 50mg & \multirow[t]{2}{*}{30 Cápsulas } & $\mathrm{R} \$ 23,77$ & $\mathrm{R} \$ 43,64$ & $-46 \%$ \\
\hline Pamelor 50mg & & $\mathrm{R} \$ 54,87$ & $\mathrm{R} \$ 67,19$ & $-18 \%$ \\
\hline Cloridrato de Nortriptilina $75 \mathrm{mg}$ & \multirow{2}{*}{30 Cápsulas } & $\mathrm{R} \$ 32,51$ & $\mathrm{R} \$ 58,93$ & $-45 \%$ \\
\hline Pamelor 75mg & & $\mathrm{R} \$ 77,74$ & $\mathrm{R} \$ 90,70$ & $-14 \%$ \\
\hline Cloridrato de Propafenona 300mg & \multirow{2}{*}{$\begin{array}{l}30 \text { Comprimidos } \\
\text { Revestidos }\end{array}$} & $\mathrm{R} \$ 34,16$ & $\mathrm{R} \$ 71,84$ & $-52 \%$ \\
\hline Ritmonorm 300mg & & $\mathrm{R} \$ 95,69$ & $\mathrm{R} \$ 110,53$ & $-13 \%$ \\
\hline Cloridrato de Propafenona 300mg & \multirow{2}{*}{$\begin{array}{l}60 \text { Comprimidos } \\
\text { Revestidos }\end{array}$} & $\mathrm{R} \$ 66,15$ & $\mathrm{R} \$ 143,67$ & $-54 \%$ \\
\hline Ritmonorm 300mg & & $\mathrm{R} \$ 189,34$ & $\mathrm{R} \$ 221,08$ & $-14 \%$ \\
\hline Cloridrato de Sertralina 100mg & \multirow{2}{*}{$\begin{array}{l}30 \text { Comprimidos } \\
\text { Revestidos }\end{array}$} & $\mathrm{R} \$ 70,36$ & $\mathrm{R} \$ 151,65$ & $-54 \%$ \\
\hline Zoloft 100mg & & $\mathrm{R} \$ 178,99$ & $\mathrm{R} \$ 233,30$ & $-23 \%$ \\
\hline Cloridrato de Sertralina 100mg & \multirow{2}{*}{$\begin{array}{l}14 \text { Comprimidos } \\
\text { Revestidos }\end{array}$} & $\mathrm{R} \$ 51,79$ & $\mathrm{R} \$ 106,97$ & $-52 \%$ \\
\hline Zoloft 100mg & & $\mathrm{R} \$ 90,99$ & $\mathrm{R} \$ 108,87$ & $-16 \%$ \\
\hline Cloridrato de Sertralina 50mg & \multirow{2}{*}{$\begin{array}{l}30 \text { Comprimidos } \\
\text { Revestidos }\end{array}$} & $\mathrm{R} \$ 29,35$ & $\mathrm{R} \$ 84,64$ & $-65 \%$ \\
\hline Zoloft 50mg & & $\mathrm{R} \$ 84,26$ & $\mathrm{R} \$ 108,51$ & $-22 \%$ \\
\hline
\end{tabular}


Quadro 3. Dados analisados $(\mathrm{n}=268)$.

\begin{tabular}{|c|c|c|c|c|}
\hline Medicamento (genérico; referência) & $\begin{array}{c}\text { Forma } \\
\text { farmacêutica } \\
\text { (quantidade) }\end{array}$ & $\begin{array}{c}\text { Preço médio } \\
\text { praticado } \\
\text { (genérico; } \\
\text { referência) } \\
\text { (A) }\end{array}$ & $\begin{array}{c}\text { PMC médio } \\
(20 \%) \\
\text { (genérico; } \\
\text { referência) } \\
\text { (B) }\end{array}$ & $\begin{array}{c}\text { Diferença } \\
\text { entre preço } \\
\text { e PMC } \\
{[(1-A /} \\
\left.\text { B })^{\star} 100\right]\end{array}$ \\
\hline Cloridrato de Tansulosina $0,4 \mathrm{mg}$ & \multirow[t]{2}{*}{30 Comprimidos } & $\mathrm{R} \$ 54,51$ & $\mathrm{R} \$ 114,89$ & $-53 \%$ \\
\hline Secotex $0,4 \mathrm{mg}$ & & $\mathrm{R} \$ 124,00$ & $\mathrm{R} \$ 176,75$ & $-30 \%$ \\
\hline Cloridrato de Tramadol 50mg & \multirow[t]{2}{*}{10 Cápsulas } & $\mathrm{R} \$ 18,36$ & $\mathrm{R} \$ 35,35$ & $-48 \%$ \\
\hline Tramal 50mg & & $\mathrm{R} \$ 49,79$ & $\mathrm{R} \$ 63,16$ & $-21 \%$ \\
\hline Cloridrato de Trazodona 100mg & \multirow{2}{*}{$\begin{array}{l}30 \text { Comprimidos } \\
\text { Revestidos }\end{array}$} & $\mathrm{R} \$ 31,39$ & $\mathrm{R} \$ 60,11$ & $-48 \%$ \\
\hline Donaren 100mg & & $\mathrm{R} \$ 73,99$ & $\mathrm{R} \$ 92,47$ & $-20 \%$ \\
\hline Cloridrato de Trazodona 50mg & \multirow{2}{*}{$\begin{array}{l}60 \text { Comprimidos } \\
\text { Revestidos }\end{array}$} & $\mathrm{R} \$ 31,44$ & $\mathrm{R} \$ 60,12$ & $-48 \%$ \\
\hline Donaren 50mg & & $\mathrm{R} \$ 57,72$ & $\mathrm{R} \$ 92,49$ & $-38 \%$ \\
\hline Cloridrato de Valaciclovir 500mg & \multirow{2}{*}{$\begin{array}{l}10 \text { Comprimidos } \\
\text { Revestidos }\end{array}$} & $\mathrm{R} \$ 58,38$ & $\mathrm{R} \$ 109,01$ & $-46 \%$ \\
\hline Valtrex 500mg & & $\mathrm{R} \$ 151,55$ & $\mathrm{R} \$ 178,45$ & $-15 \%$ \\
\hline Cloridrato de Valaciclovir 500mg & \multirow{2}{*}{$\begin{array}{l}42 \text { Comprimidos } \\
\text { Revestidos }\end{array}$} & $\mathrm{R} \$ 281,10$ & $\mathrm{R} \$ 441,72$ & $-36 \%$ \\
\hline Valtrex 500mg & & $\mathrm{R} \$ 515,99$ & $\mathrm{R} \$ 672,94$ & $-23 \%$ \\
\hline Cloridrato de Venlafaxina 150mg & \multirow{2}{*}{$\begin{array}{l}30 \text { Cápsulas } \\
\text { de Liberação } \\
\text { Prolongada }\end{array}$} & $\mathrm{R} \$ 110,99$ & $\mathrm{R} \$ 223,27$ & $-50 \%$ \\
\hline Efexor XR 150mg & & $\mathrm{R} \$ 420,99$ & $\mathrm{R} \$ 520,53$ & $-19 \%$ \\
\hline Cloridrato de Venlafaxina $37,5 \mathrm{mg}$ & \multirow{2}{*}{$\begin{array}{l}30 \text { Cápsulas Duras } \\
\text { de Liberação } \\
\text { Prolongada }\end{array}$} & $\mathrm{R} \$ 40,25$ & $\mathrm{R} \$ 76,72$ & $-48 \%$ \\
\hline Efexor XR 37,5mg & & $\mathrm{R} \$ 114,49$ & $\mathrm{R} \$ 156,81$ & $-27 \%$ \\
\hline Cloridrato de Venlafaxina 75mg & \multirow{2}{*}{$\begin{array}{l}30 \text { Cápsulas Duras } \\
\text { de Liberação } \\
\text { Prolongada }\end{array}$} & $\mathrm{R} \$ 70,43$ & $R \$ 130,05$ & $-46 \%$ \\
\hline Efexor XR 75mg & & $\mathrm{R} \$ 300,99$ & $\mathrm{R} \$ 366,97$ & $-18 \%$ \\
\hline Colchicina $0,5 \mathrm{mg}$ & \multirow[t]{2}{*}{20 Comprimidos } & $\mathrm{R} \$ 14,78$ & $\mathrm{R} \$ 24,61$ & $-40 \%$ \\
\hline Colchis $0,5 \mathrm{mg}$ & & $\mathrm{R} \$ 23,28$ & $\mathrm{R} \$ 40,30$ & $-42 \%$ \\
\hline Colchicina $0,5 \mathrm{mg}$ & \multirow[t]{2}{*}{30 Comprimidos } & $\mathrm{R} \$ 18,96$ & $\mathrm{R} \$ 39,29$ & $-52 \%$ \\
\hline Colchis $0,5 \mathrm{mg}$ & & $\mathrm{R} \$ 31,89$ & $\mathrm{R} \$ 60,47$ & $-47 \%$ \\
\hline Desloratadina 5mg & \multirow{2}{*}{$\begin{array}{l}10 \text { Comprimidos } \\
\text { Revestidos }\end{array}$} & $\mathrm{R} \$ 24,12$ & $\mathrm{R} \$ 43,63$ & $-45 \%$ \\
\hline Desalex 5mg & & $\mathrm{R} \$ 50,40$ & $\mathrm{R} \$ 59,52$ & $-15 \%$ \\
\hline Desloratadina $0,5 \mathrm{mg} / \mathrm{ml}$ & \multirow[t]{2}{*}{ 100ml Xarope } & $\mathrm{R} \$ 34,42$ & $\mathrm{R} \$ 59,14$ & $-42 \%$ \\
\hline Desalex $0,5 \mathrm{mg} / \mathrm{ml}$ & & $\mathrm{R} \$ 54,86$ & $\mathrm{R} \$ 68,15$ & $-20 \%$ \\
\hline Desloratadina 5mg & \multirow{2}{*}{$\begin{array}{l}30 \text { Comprimidos } \\
\text { Revestidos }\end{array}$} & $\mathrm{R} \$ 57,11$ & $\mathrm{R} \$ 124,45$ & $-54 \%$ \\
\hline Desalex 5mg & & $\mathrm{R} \$ 70,88$ & $\mathrm{R} \$ 92,41$ & $-23 \%$ \\
\hline Desloratadina $0,5 \mathrm{mg} / \mathrm{ml}$ & \multirow[t]{2}{*}{ 60ml Xarope } & $\mathrm{R} \$ 21,45$ & $\mathrm{R} \$ 35,83$ & $-40 \%$ \\
\hline Desalex $0,5 \mathrm{mg} / \mathrm{ml}$ & & $\mathrm{R} \$ 37,98$ & $\mathrm{R} \$ 47,64$ & $-20 \%$ \\
\hline Desogestrel 0,075mg & \multirow{2}{*}{$\begin{array}{l}28 \text { Comprimidos } \\
\text { Revestidos }\end{array}$} & $\mathrm{R} \$ 15,61$ & $\mathrm{R} \$ 28,93$ & $-46 \%$ \\
\hline Cerazette $75 \mathrm{mcg}$ & & $\mathrm{R} \$ 35,32$ & $\mathrm{R} \$ 44,54$ & $-21 \%$ \\
\hline Desogestrel 0,075mg & \multirow{2}{*}{$\begin{array}{l}84 \text { Comprimidos } \\
\text { Revestidos }\end{array}$} & $\mathrm{R} \$ 38,49$ & $\mathrm{R} \$ 74,83$ & $-49 \%$ \\
\hline Cerazette $75 \mathrm{mcg}$ & & $\mathrm{R} \$ 82,74$ & $\mathrm{R} \$ 133,64$ & $-38 \%$ \\
\hline Diazepam 10mg & \multirow[t]{2}{*}{30 Comprimidos } & $\mathrm{R} \$ 11,37$ & $\mathrm{R} \$ 15,73$ & $-28 \%$ \\
\hline Valium 10mg & & $\mathrm{R} \$ 21,72$ & $\mathrm{R} \$ 25,12$ & $-14 \%$ \\
\hline Diazepam 5mg & \multirow[t]{2}{*}{30 Comprimidos } & $\mathrm{R} \$ 8,39$ & $\mathrm{R} \$ 11,63$ & $-28 \%$ \\
\hline Valium 5mg & & $\mathrm{R} \$ 15,66$ & $\mathrm{R} \$ 18,84$ & $-17 \%$ \\
\hline Dicloridrato de Cetirizina 10mg & \multirow{2}{*}{$\begin{array}{l}12 \text { Comprimidos } \\
\text { Revestidos }\end{array}$} & $\mathrm{R} \$ 21,90$ & $\mathrm{R} \$ 40,09$ & $-45 \%$ \\
\hline Zyrtec 10mg & & $\mathrm{R} \$ 51,41$ & $\mathrm{R} \$ 63,41$ & $-19 \%$ \\
\hline Dicloridrato de Cetirizina $1 \mathrm{mg} / \mathrm{ml}$ & \multirow{2}{*}{$\begin{array}{l}\text { 120ml Solução } \\
\text { Oral }\end{array}$} & $\mathrm{R} \$ 21,70$ & $\mathrm{R} \$ 34,07$ & $-36 \%$ \\
\hline Zyrtec $1 \mathrm{mg} / \mathrm{ml}$ & & $\mathrm{R} \$ 46,45$ & $\mathrm{R} \$ 55,46$ & $-16 \%$ \\
\hline Dicloridrato de Levocetirizina 5mg & \multirow{2}{*}{$\begin{array}{l}10 \text { Comprimidos } \\
\text { Revestidos }\end{array}$} & $\mathrm{R} \$ 21,86$ & $\mathrm{R} \$ 33,52$ & $-35 \%$ \\
\hline Zyxem 5mg & & $\mathrm{R} \$ 43,77$ & $\mathrm{R} \$ 51,56$ & $-15 \%$ \\
\hline Dicloridrato de Pramipexol 1mg & \multirow[t]{2}{*}{30 Comprimidos } & $\mathrm{R} \$ 85,11$ & $\mathrm{R} \$ 229,98$ & $-63 \%$ \\
\hline Sifrol 1mg & & $\mathrm{R} \$ 307,58$ & $\mathrm{R} \$ 353,79$ & $-13 \%$ \\
\hline
\end{tabular}


Quadro 3. Dados analisados $(\mathrm{n}=268)$.

\begin{tabular}{|c|c|c|c|c|}
\hline Medicamento (genérico; referência) & $\begin{array}{c}\text { Forma } \\
\text { farmacêutica } \\
\text { (quantidade) }\end{array}$ & $\begin{array}{l}\text { Preço médio } \\
\text { praticado } \\
\text { (genérico; } \\
\text { referência) } \\
\text { (A) }\end{array}$ & $\begin{array}{l}\text { PMC médio } \\
(20 \%) \\
\text { (genérico; } \\
\text { referência) } \\
(B)\end{array}$ & $\begin{array}{c}\text { Diferença } \\
\text { entre preço } \\
\text { e PMC } \\
{[(1-A /} \\
\left.\text { B })^{\star} 100\right] \\
\end{array}$ \\
\hline Divalproato de Sódio $250 \mathrm{mg}$ & \multirow{2}{*}{$\begin{array}{l}30 \text { Comprimidos } \\
\text { Revestidos }\end{array}$} & $\mathrm{R} \$ 25,47$ & $\mathrm{R} \$ 36,98$ & $-31 \%$ \\
\hline Depakote $250 \mathrm{mg}$ & & $\mathrm{R} \$ 49,77$ & $\mathrm{R} \$ 58,50$ & $-15 \%$ \\
\hline Divalproato de Sódio 500mg & \multirow{2}{*}{$\begin{array}{l}30 \text { Comprimidos } \\
\text { Revestidos }\end{array}$} & $\mathrm{R} \$ 44,72$ & $\mathrm{R} \$ 68,93$ & $-35 \%$ \\
\hline Depakote 500mg & & $\mathrm{R} \$ 83,99$ & $\mathrm{R} \$ 109,05$ & $-23 \%$ \\
\hline Divalproato de Sódio $125 \mathrm{mg}$ & \multirow[t]{2}{*}{30 Cápsulas } & $\mathrm{R} \$ 19,99$ & $\mathrm{R} \$ 21,57$ & $-7 \%$ \\
\hline Depakote Sprinkle 125mg & & $\mathrm{R} \$ 27,64$ & $\mathrm{R} \$ 34,35$ & $-20 \%$ \\
\hline $\begin{array}{l}\text { Enantato de Norestisterona 50mg + Valerato de } \\
\text { Estradiol } 5 \mathrm{mg}\end{array}$ & \multirow[t]{2}{*}{$\begin{array}{l}1 \text { Ampola } \\
\text { Injetável } 1 \mathrm{ml}\end{array}$} & $\mathrm{R} \$ 14,53$ & $\mathrm{R} \$ 22,25$ & $-35 \%$ \\
\hline Mesigyna 50mg + 5mg & & $\mathrm{R} \$ 29,36$ & $\mathrm{R} \$ 34,69$ & $-15 \%$ \\
\hline Fenobarbital 40mg & \multirow[t]{2}{*}{ 20ml Solução Oral } & $\mathrm{R} \$ 3,74$ & $\mathrm{R} \$ 6,21$ & $-40 \%$ \\
\hline Gardenal 40mg & & $\mathrm{R} \$ 8,22$ & $\mathrm{R} \$ 9,69$ & $-15 \%$ \\
\hline Furosemida 40mg & \multirow[t]{2}{*}{20 Comprimidos } & $\mathrm{R} \$ 4,66$ & $\mathrm{R} \$ 8,64$ & $-46 \%$ \\
\hline Lasix 40mg & & $\mathrm{R} \$ 14,45$ & $\mathrm{R} \$ 18,57$ & $-22 \%$ \\
\hline Gabapentina 300mg & \multirow{2}{*}{$\begin{array}{l}30 \text { Cápsulas } \\
\text { Gelatinosas Duras }\end{array}$} & $\mathrm{R} \$ 43,72$ & $\mathrm{R} \$ 110,05$ & $-60 \%$ \\
\hline Neurontin 300mg & & $\mathrm{R} \$ 142,99$ & $\mathrm{R} \$ 165,24$ & $-13 \%$ \\
\hline Gabapentina 400mg & \multirow{2}{*}{$\begin{array}{l}0 \text { Cápsulas } \\
\text { Gelatinosas Duras }\end{array}$} & $\mathrm{R} \$ 54,24$ & $\mathrm{R} \$ 131,47$ & $-59 \%$ \\
\hline Neurontin 400mg & & $\mathrm{R} \$ 166,99$ & $\mathrm{R} \$ 201,10$ & $-17 \%$ \\
\hline Hemitartarato de Zolpidem 10mg & \multirow{2}{*}{$\begin{array}{l}20 \text { Comprimidos } \\
\text { Revestidos }\end{array}$} & $\mathrm{R} \$ 29,25$ & $\mathrm{R} \$ 50,71$ & $-42 \%$ \\
\hline Stilnox 10mg & & $\mathrm{R} \$ 62,69$ & $\mathrm{R} \$ 78,52$ & $-20 \%$ \\
\hline Indapamida $1,5 \mathrm{mg}$ & \multirow{2}{*}{$\begin{array}{l}30 \text { Comprimidos } \\
\text { Revestidos } \\
\text { de Liberação } \\
\text { Prolongada } \\
\end{array}$} & $\mathrm{R} \$ 14,80$ & $\mathrm{R} \$ 28,65$ & $-48 \%$ \\
\hline Natrilix SR 1,5mg & & $\mathrm{R} \$ 32,70$ & $\mathrm{R} \$ 42,81$ & $-24 \%$ \\
\hline Lamotrigina 50mg & \multirow[t]{2}{*}{30 Comprimidos } & $\mathrm{R} \$ 29,78$ & $\mathrm{R} \$ 58,13$ & $-49 \%$ \\
\hline Lamictal 50mg & & $\mathrm{R} \$ 114,72$ & $\mathrm{R} \$ 251,22$ & $-54 \%$ \\
\hline Lamotrigina $25 \mathrm{mg}$ & \multirow[t]{2}{*}{30 Comprimidos } & $\mathrm{R} \$ 23,09$ & $\mathrm{R} \$ 43,59$ & $-47 \%$ \\
\hline Lamictal 25mg & & $\mathrm{R} \$ 79,24$ & $\mathrm{R} \$ 141,20$ & $-44 \%$ \\
\hline Lamotrigina $100 \mathrm{mg}$ & \multirow[t]{2}{*}{30 Comprimidos } & $\mathrm{R} \$ 44,86$ & $\mathrm{R} \$ 104,67$ & $-57 \%$ \\
\hline Lamictal 100mg & & $\mathrm{R} \$ 233,32$ & $\mathrm{R} \$ 439,74$ & $-47 \%$ \\
\hline Latanoprosta $50 \mathrm{mcg} / \mathrm{ml}$ & \multirow{2}{*}{$\begin{array}{l}\text { 2,5ml Solução } \\
\text { Oftálmica }\end{array}$} & $\mathrm{R} \$ 61,07$ & $\mathrm{R} \$ 117,40$ & $-48 \%$ \\
\hline Xalatan $50 \mathrm{mcg} / \mathrm{ml}$ & & $\mathrm{R} \$ 151,84$ & $\mathrm{R} \$ 180,62$ & $-16 \%$ \\
\hline Latanoprosta 50mcg + Maleato de Timolol 5mg & \multirow{2}{*}{$\begin{array}{l}2,5 \mathrm{ml} \text { Solução } \\
\text { Oftálmica }\end{array}$} & $\mathrm{R} \$ 84,72$ & $\mathrm{R} \$ 131,88$ & $-36 \%$ \\
\hline Xalacom & & $\mathrm{R} \$ 168,52$ & $\mathrm{R} \$ 194,48$ & $-13 \%$ \\
\hline Levotiroxina Sódica $100 \mathrm{mcg}$ & \multirow[t]{2}{*}{30 Comprimidos } & $\mathrm{R} \$ 5,03$ & $\mathrm{R} \$ 8,35$ & $-40 \%$ \\
\hline Puran T4 100mcg & & $\mathrm{R} \$ 10,29$ & $\mathrm{R} \$ 12,88$ & $-20 \%$ \\
\hline Levotiroxina Sódica $112 \mathrm{mcg}$ & \multirow[t]{2}{*}{30 Comprimidos } & $\mathrm{R} \$ 9,74$ & $\mathrm{R} \$ 16,42$ & $-41 \%$ \\
\hline Puran T4 112mcg & & $\mathrm{R} \$ 19,66$ & $\mathrm{R} \$ 25,27$ & $-22 \%$ \\
\hline Levotiroxina Sódica $125 \mathrm{mcg}$ & \multirow[t]{2}{*}{30 Comprimidos } & $\mathrm{R} \$ 7,36$ & $\mathrm{R} \$ 12,25$ & $-40 \%$ \\
\hline Puran T4 125mcg & & $\mathrm{R} \$ 14,99$ & $\mathrm{R} \$ 18,88$ & $-21 \%$ \\
\hline Levotiroxina Sódica $150 \mathrm{mcg}$ & \multirow[t]{2}{*}{30 Comprimidos } & $\mathrm{R} \$ 7,82$ & $\mathrm{R} \$ 13,19$ & $-41 \%$ \\
\hline Puran T4 150mcg & & $\mathrm{R} \$ 15,95$ & $\mathrm{R} \$ 20,28$ & $-21 \%$ \\
\hline Levotiroxina Sódica $175 \mathrm{mcg}$ & \multirow[t]{2}{*}{30 Comprimidos } & $\mathrm{R} \$ 9,90$ & $\mathrm{R} \$ 16,64$ & $-41 \%$ \\
\hline Puran T4 175mcg & & $\mathrm{R} \$ 20,09$ & $\mathrm{R} \$ 25,63$ & $-22 \%$ \\
\hline Levotiroxina Sódica $200 \mathrm{mcg}$ & \multirow[t]{2}{*}{30 Comprimidos } & $\mathrm{R} \$ 15,06$ & $\mathrm{R} \$ 28,81$ & $-48 \%$ \\
\hline Puran T4 200mcg & & $\mathrm{R} \$ 34,87$ & $\mathrm{R} \$ 44,33$ & $-21 \%$ \\
\hline Levotiroxina Sódica 25mcg & \multirow[t]{2}{*}{30 Comprimidos } & $\mathrm{R} \$ 5,30$ & $\mathrm{R} \$ 8,85$ & $-40 \%$ \\
\hline Puran T4 25mcg & & $\mathrm{R} \$ 11,23$ & $\mathrm{R} \$ 13,64$ & $-18 \%$ \\
\hline
\end{tabular}


Quadro 3. Dados analisados $(\mathrm{n}=268)$.

\begin{tabular}{|c|c|c|c|c|}
\hline Medicamento (genérico; referência) & $\begin{array}{c}\text { Forma } \\
\text { farmacêutica } \\
\text { (quantidade) }\end{array}$ & $\begin{array}{l}\text { Preço médio } \\
\text { praticado } \\
\text { (genérico; } \\
\text { referência) } \\
\text { (A) }\end{array}$ & \begin{tabular}{|} 
PMC médio \\
$(20 \%)$ \\
(genérico; \\
referência) \\
(B)
\end{tabular} & 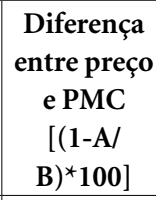 \\
\hline Levotiroxina Sódica 50mcg & \multirow[t]{2}{*}{30 Comprimidos } & $\mathrm{R} \$ 5,82$ & $\mathrm{R} \$ 9,80$ & $-41 \%$ \\
\hline Puran T4 50mcg & & $\mathrm{R} \$ 12,52$ & $\mathrm{R} \$ 15,11$ & $-17 \%$ \\
\hline Levotiroxina Sódica $75 \mathrm{mcg}$ & \multirow[t]{2}{*}{30 Comprimidos } & $\mathrm{R} \$ 6,37$ & $\mathrm{R} \$ 10,71$ & $-41 \%$ \\
\hline Puran T4 75mcg & & $\mathrm{R} \$ 12,53$ & $\mathrm{R} \$ 16,48$ & $-24 \%$ \\
\hline Levotiroxina Sódica $88 \mathrm{mcg}$ & \multirow[t]{2}{*}{30 Comprimidos } & $\mathrm{R} \$ 7,65$ & $\mathrm{R} \$ 12,90$ & $-41 \%$ \\
\hline Puran T4 88mcg & & $\mathrm{R} \$ 15,03$ & $\mathrm{R} \$ 19,85$ & $-24 \%$ \\
\hline Loratadina $1 \mathrm{mg} / \mathrm{Ml}$ & \multirow[t]{2}{*}{ 100ml Xarope } & $\mathrm{R} \$ 17,50$ & $\mathrm{R} \$ 23,53$ & $-26 \%$ \\
\hline Claritin $1 \mathrm{mg} / \mathrm{ml}$ & & $\mathrm{R} \$ 41,27$ & $\mathrm{R} \$ 49,42$ & $-16 \%$ \\
\hline Loratadina 10mg & \multirow[t]{2}{*}{12 Comprimidos } & $\mathrm{R} \$ 22,90$ & $\mathrm{R} \$ 37,30$ & $-39 \%$ \\
\hline Claritin 10mg & & $\mathrm{R} \$ 46,29$ & $\mathrm{R} \$ 53,83$ & $-14 \%$ \\
\hline Maleato de Dexclorfeniramina $0,4 \mathrm{mg} / \mathrm{ml}$ & \multirow{2}{*}{$\begin{array}{l}\text { 120ml Solução } \\
\text { Oral }\end{array}$} & $\mathrm{R} \$ 11,25$ & $\mathrm{R} \$ 15,28$ & $-26 \%$ \\
\hline Polaramine $0,4 \mathrm{mg} / \mathrm{ml}$ & & $\mathrm{R} \$ 22,71$ & $\mathrm{R} \$ 24,70$ & $-8 \%$ \\
\hline Maleato de Dexclorfeniramina 2mg & \multirow[t]{2}{*}{20 Comprimidos } & $\mathrm{R} \$ 7,79$ & $\mathrm{R} \$ 11,01$ & $-29 \%$ \\
\hline Polaramine $2 \mathrm{mg}$ & & $\mathrm{R} \$ 17,91$ & $\mathrm{R} \$ 19,71$ & $-9 \%$ \\
\hline Maleato de Dexclorfeniramina 10mg & \multirow{2}{*}{$\begin{array}{l}30 \mathrm{~g} \text { Creme } \\
\text { Dermatológico }\end{array}$} & $\mathrm{R} \$ 9,71$ & $\mathrm{R} \$ 11,74$ & $-17 \%$ \\
\hline Polaramine $10 \mathrm{mg}$ & & $\mathrm{R} \$ 16,32$ & $\mathrm{R} \$ 18,14$ & $-10 \%$ \\
\hline $\begin{array}{l}\text { Maleato de Dexclorfeniramina } 0,4 \mathrm{mg}+ \\
\text { Betametasona } 0,05 \mathrm{mg}\end{array}$ & \multirow[t]{2}{*}{ 120ml Xarope } & $\mathrm{R} \$ 15,29$ & $\mathrm{R} \$ 33,16$ & $-54 \%$ \\
\hline Celestamine & & $\mathrm{R} \$ 41,39$ & $\mathrm{R} \$ 51,59$ & $-20 \%$ \\
\hline Maleato de Midazolam 15mg & \multirow{2}{*}{$\begin{array}{l}30 \text { Comprimidos } \\
\text { Revestidos }\end{array}$} & $\mathrm{R} \$ 38,39$ & $\mathrm{R} \$ 70,41$ & $-45 \%$ \\
\hline Dormonid 15mg & & $\mathrm{R} \$ 85,74$ & $\mathrm{R} \$ 108,42$ & $-21 \%$ \\
\hline Maleato de Timolol 0,5\% & \multirow{2}{*}{$\begin{array}{l}5 \mathrm{ml} \text { Solução } \\
\text { Oftálmica }\end{array}$} & $\mathrm{R} \$ 5,36$ & $\mathrm{R} \$ 11,19$ & $-52 \%$ \\
\hline Timoptol 0,5\% & & $\mathrm{R} \$ 14,03$ & $\mathrm{R} \$ 17,16$ & $-18 \%$ \\
\hline Metronidazol 250mg & \multirow[t]{2}{*}{20 Comprimidos } & $\mathrm{R} \$ 8,11$ & $\mathrm{R} \$ 12,61$ & $-36 \%$ \\
\hline Flagyl 250mg & & $\mathrm{R} \$ 18,29$ & $\mathrm{R} \$ 20,07$ & $-9 \%$ \\
\hline Metronidazol 100mg/g & \multirow[t]{2}{*}{ 50g Geléia Vaginal } & $\mathrm{R} \$ 18,02$ & $\mathrm{R} \$ 29,49$ & $-39 \%$ \\
\hline Flagyl 100mg/g & & $\mathrm{R} \$ 39,89$ & $\mathrm{R} \$ 46,82$ & $-15 \%$ \\
\hline Mirtazapina $15 \mathrm{mg}$ & \multirow{2}{*}{$\begin{array}{l}30 \text { Comprimidos } \\
\text { Orodispersíveis }\end{array}$} & $\mathrm{R} \$ 60,99$ & $\mathrm{R} \$ 90,74$ & $-33 \%$ \\
\hline Remeron Soltab 15mg & & $\mathrm{R} \$ 89,49$ & $\mathrm{R} \$ 139,59$ & $-36 \%$ \\
\hline Mirtazapina 30mg & \multirow{2}{*}{$\begin{array}{l}30 \text { Comprimidos } \\
\text { Orodispersíveis }\end{array}$} & $\mathrm{R} \$ 108,59$ & $\mathrm{R} \$ 181,53$ & $-40 \%$ \\
\hline Remeron Soltab 30mg & & $\mathrm{R} \$ 176,99$ & $\mathrm{R} \$ 279,28$ & $-37 \%$ \\
\hline Mirtazapina 45mg & \multirow{2}{*}{$\begin{array}{l}30 \text { Comprimidos } \\
\text { Orodispersíveis }\end{array}$} & $\mathrm{R} \$ 170,99$ & $\mathrm{R} \$ 258,07$ & $-34 \%$ \\
\hline Remeron Soltab 45mg & & $\mathrm{R} \$ 176,99$ & $\mathrm{R} \$ 397,05$ & $-55 \%$ \\
\hline Nistatina $100.000 \mathrm{UI} / \mathrm{g}+$ Óxido de Zinco $200 \mathrm{mg} / \mathrm{g}$ & \multirow[t]{2}{*}{$60 \mathrm{~g}$ Pomada } & $\mathrm{R} \$ 17,05$ & $\mathrm{R} \$ 32,90$ & $-48 \%$ \\
\hline Dermodex & & $\mathrm{R} \$ 47,75$ & $\mathrm{R} \$ 64,97$ & $-27 \%$ \\
\hline Nitrato de Fenticonazol $0,02 \mathrm{~g} / \mathrm{g}$ & \multirow{2}{*}{$\begin{array}{l}40 \mathrm{~g} \text { Creme } \\
\text { Vaginal }\end{array}$} & $\mathrm{R} \$ 27,22$ & $\mathrm{R} \$ 42,74$ & $-36 \%$ \\
\hline Fentizol $0,02 \mathrm{~g} / \mathrm{g}$ & & $\mathrm{R} \$ 29,95$ & $\mathrm{R} \$ 67,30$ & $-55 \%$ \\
\hline Nitrazepam 5mg & \multirow[t]{2}{*}{20 Comprimidos } & $\mathrm{R} \$ 6,78$ & $\mathrm{R} \$ 10,95$ & $-38 \%$ \\
\hline Sonebon $5 \mathrm{mg}$ & & $\mathrm{R} \$ 9,92$ & $\mathrm{R} \$ 11,68$ & $-15 \%$ \\
\hline Olanzapina 10mg & \multirow{2}{*}{$\begin{array}{l}30 \text { Comprimidos } \\
\text { Revestidos }\end{array}$} & $\mathrm{R} \$ 323,36$ & $\mathrm{R} \$ 701,28$ & $-54 \%$ \\
\hline Zyprexa 10mg & & $\mathrm{R} \$ 1.149,49$ & $\mathrm{R} \$ 1.253,68$ & $-8 \%$ \\
\hline Olanzapina $2,5 \mathrm{mg}$ & \multirow{2}{*}{$\begin{array}{l}30 \text { Comprimidos } \\
\text { Revestidos }\end{array}$} & $\mathrm{R} \$ 88,11$ & $\mathrm{R} \$ 250,18$ & $-65 \%$ \\
\hline Zyprexa 2,5mg & & $\mathrm{R} \$ 388,99$ & $\mathrm{R} \$ 424,34$ & $-8 \%$ \\
\hline Olanzapina 5mg & \multirow{2}{*}{$\begin{array}{l}30 \text { Comprimidos } \\
\text { Revestidos }\end{array}$} & $\mathrm{R} \$ 122,66$ & $\mathrm{R} \$ 407,42$ & $-70 \%$ \\
\hline Zyprexa 5mg & & $\mathrm{R} \$ 574,99$ & $\mathrm{R} \$ 626,80$ & $-8 \%$ \\
\hline Oxalato de Escitalopram 10mg & \multirow{2}{*}{$\begin{array}{l}30 \text { Comprimidos } \\
\text { Revestidos }\end{array}$} & $\mathrm{R} \$ 39,02$ & $\mathrm{R} \$ 155,49$ & $-75 \%$ \\
\hline Lexapro 10mg & & $\mathrm{R} \$ 169,60$ & $\mathrm{R} \$ 294,87$ & $-42 \%$ \\
\hline
\end{tabular}


Quadro 3. Dados analisados ( $\mathrm{n}=268)$.

\begin{tabular}{|c|c|c|c|c|}
\hline Medicamento (genérico; referência) & $\begin{array}{c}\text { Forma } \\
\text { farmacêutica } \\
\text { (quantidade) }\end{array}$ & $\begin{array}{l}\text { Preço médio } \\
\text { praticado } \\
\text { (genérico; } \\
\text { referência) } \\
\text { (A) }\end{array}$ & $\begin{array}{c}\text { PMC médio } \\
(20 \%) \\
\text { (genérico; } \\
\text { referência) } \\
\text { (B) }\end{array}$ & $\begin{array}{c}\text { Diferença } \\
\text { entre preço } \\
\text { e PMC } \\
{[(1-A /} \\
\left.\text { B })^{*} 100\right]\end{array}$ \\
\hline Oxalato de Escitalopram 15mg & \multirow{2}{*}{$\begin{array}{l}30 \text { Comprimidos } \\
\text { Revestidos }\end{array}$} & $\mathrm{R} \$ 67,19$ & $\mathrm{R} \$ 209,33$ & $-68 \%$ \\
\hline Lexapro $15 \mathrm{mg}$ & & $\mathrm{R} \$ 168,49$ & $\mathrm{R} \$ 353,95$ & $-52 \%$ \\
\hline Oxalato de Escitalopram 20mg & \multirow{2}{*}{$\begin{array}{l}30 \text { Comprimidos } \\
\text { Revestidos }\end{array}$} & $\mathrm{R} \$ 87,29$ & $\mathrm{R} \$ 280,09$ & $-69 \%$ \\
\hline Lexapro $20 \mathrm{mg}$ & & $\mathrm{R} \$ 251,63$ & $\mathrm{R} \$ 560,46$ & $-55 \%$ \\
\hline Oxalato de Escitalopram 10mg & \multirow[t]{2}{*}{60 Comprimidos } & $\mathrm{R} \$ 64,49$ & $\mathrm{R} \$ 383,56$ & $-83 \%$ \\
\hline Lexapro $10 \mathrm{mg}$ & & $\mathrm{R} \$ 174,99$ & - & - \\
\hline Oxalato de Escitalopram $20 \mathrm{mg} / \mathrm{ml}$ & \multirow[t]{2}{*}{ 15ml Solução Oral } & $\mathrm{R} \$ 48,39$ & $\mathrm{R} \$ 191,73$ & $-75 \%$ \\
\hline Lexapro $20 \mathrm{mg} / \mathrm{ml}$ & & $\mathrm{R} \$ 267,49$ & $\mathrm{R} \$ 294,89$ & $-9 \%$ \\
\hline Oxcarbazepina 300mg & \multirow{2}{*}{$\begin{array}{l}60 \text { Comprimidos } \\
\text { Revestidos }\end{array}$} & $\mathrm{R} \$ 47,89$ & $\mathrm{R} \$ 98,50$ & $-51 \%$ \\
\hline Trileptal 300mg & & $\mathrm{R} \$ 150,32$ & $\mathrm{R} \$ 174,17$ & $-14 \%$ \\
\hline Oxcarbazepina 600mg & \multirow{2}{*}{$\begin{array}{l}60 \text { Comprimidos } \\
\text { Revestidos }\end{array}$} & $\mathrm{R} \$ 82,74$ & $\mathrm{R} \$ 192,59$ & $-57 \%$ \\
\hline Trileptal 600mg & & $\mathrm{R} \$ 286,99$ & $\mathrm{R} \$ 334,16$ & $-14 \%$ \\
\hline Paracetamol 500mg + Fosfato de Codeína 30mg & \multirow[t]{2}{*}{12 Comprimidos } & $\mathrm{R} \$ 12,82$ & $\mathrm{R} \$ 20,56$ & $-38 \%$ \\
\hline Tylex 30mg & & $\mathrm{R} \$ 28,67$ & $\mathrm{R} \$ 34,18$ & $-16 \%$ \\
\hline Paracetamol 500mg + Fosfato de Codeína 30mg & \multirow[t]{2}{*}{24 Comprimidos } & $\mathrm{R} \$ 23,40$ & $\mathrm{R} \$ 40,54$ & $-42 \%$ \\
\hline Tylex 30mg & & $\mathrm{R} \$ 58,99$ & $\mathrm{R} \$ 66,68$ & $-12 \%$ \\
\hline Paracetamol 500mg + Fosfato de Codeína 30mg & \multirow[t]{2}{*}{36 Comprimidos } & $\mathrm{R} \$ 32,96$ & $\mathrm{R} \$ 58,52$ & $-44 \%$ \\
\hline Tylex 30mg & & $\mathrm{R} \$ 81,99$ & $\mathrm{R} \$ 90,03$ & $-9 \%$ \\
\hline Pregabalina $75 \mathrm{mg}$ & \multirow[t]{2}{*}{28 Cápsulas Duras } & $\mathrm{R} \$ 51,09$ & $\mathrm{R} \$ 98,91$ & $-48 \%$ \\
\hline Lyrica 75mg & & $\mathrm{R} \$ 188,09$ & $\mathrm{R} \$ 152,19$ & $24 \%$ \\
\hline Succinato de Sumatriptana 50mg & \multirow{2}{*}{$\begin{array}{l}2 \text { Comprimidos } \\
\text { Revestidos }\end{array}$} & $\mathrm{R} \$ 14,95$ & $\mathrm{R} \$ 22,75$ & $-34 \%$ \\
\hline Imigran $50 \mathrm{mg}$ & & $\mathrm{R} \$ 29,80$ & $\mathrm{R} \$ 35,06$ & $-15 \%$ \\
\hline Succinato de Sumatriptana 100mg & \multirow{2}{*}{$\begin{array}{l}2 \text { Comprimidos } \\
\text { Revestidos }\end{array}$} & $\mathrm{R} \$ 26,86$ & $\mathrm{R} \$ 45,12$ & $-40 \%$ \\
\hline Imigran 100mg & & $\mathrm{R} \$ 62,72$ & $\mathrm{R} \$ 93,33$ & $-33 \%$ \\
\hline Sulfadiazina de Prata 10mg/g & \multirow[t]{2}{*}{ 30g Creme } & $\mathrm{R} \$ 14,39$ & $\mathrm{R} \$ 21,69$ & $-34 \%$ \\
\hline Dermazine $10 \mathrm{mg} / \mathrm{g}$ & & $\mathrm{R} \$ 29,31$ & $\mathrm{R} \$ 33,98$ & $-14 \%$ \\
\hline Sulfadiazina de Prata $10 \mathrm{mg} / \mathrm{g}$ & \multirow[t]{2}{*}{$50 \mathrm{~g}$ Creme } & $\mathrm{R} \$ 17,28$ & $\mathrm{R} \$ 32,22$ & $-46 \%$ \\
\hline Dermazine $10 \mathrm{mg} / \mathrm{g}$ & & $\mathrm{R} \$ 35,92$ & $\mathrm{R} \$ 42,84$ & $-16 \%$ \\
\hline Sulfato de Neomicina 5mg/g + Bacitracina 250ui/g & \multirow[t]{2}{*}{ 15g Pomada } & $\mathrm{R} \$ 6,92$ & $\mathrm{R} \$ 9,77$ & $-29 \%$ \\
\hline Nebacetin & & $\mathrm{R} \$ 13,89$ & $\mathrm{R} \$ 17,57$ & $-21 \%$ \\
\hline Sulfato de Neomicina 5mg/g + Bacitracina 250ui/g & \multirow[t]{2}{*}{$50 \mathrm{~g}$ Pomada } & $\mathrm{R} \$ 11,56$ & $\mathrm{R} \$ 21,67$ & $-47 \%$ \\
\hline Nebacetin & & $\mathrm{R} \$ 27,79$ & $\mathrm{R} \$ 36,36$ & $-24 \%$ \\
\hline Tartarato de Brimonidina $2 \mathrm{mg} / \mathrm{ml}$ & \multirow{2}{*}{$\begin{array}{l}5 \mathrm{ml} \text { Solução } \\
\text { Oftálmica }\end{array}$} & $\mathrm{R} \$ 26,18$ & $\mathrm{R} \$ 63,90$ & $-59 \%$ \\
\hline Alphagan $2 \mathrm{mg} / \mathrm{ml}$ & & $\mathrm{R} \$ 83,74$ & $\mathrm{R} \$ 98,32$ & $-15 \%$ \\
\hline Tartarato de Brimonidina $1,5 \mathrm{mg} / \mathrm{ml}$ & \multirow{2}{*}{$\begin{array}{l}\text { 5ml Solução } \\
\text { Oftálmica }\end{array}$} & $\mathrm{R} \$ 23,04$ & $\mathrm{R} \$ 53,09$ & $-57 \%$ \\
\hline Alphagan P $1,5 \mathrm{mg} / \mathrm{ml}$ & & $\mathrm{R} \$ 77,23$ & $\mathrm{R} \$ 98,32$ & $-21 \%$ \\
\hline Topiramato 50mg & \multirow{2}{*}{$\begin{array}{l}60 \text { Comprimidos } \\
\text { Revestidos }\end{array}$} & $\mathrm{R} \$ 91,82$ & $\mathrm{R} \$ 227,36$ & $-60 \%$ \\
\hline Topamax 50mg & & $\mathrm{R} \$ 225,99$ & $\mathrm{R} \$ 332,73$ & $-32 \%$ \\
\hline Topiramato $25 \mathrm{mg}$ & \multirow{2}{*}{$\begin{array}{l}60 \text { Comprimidos } \\
\text { Revestidos }\end{array}$} & $\mathrm{R} \$ 47,25$ & $\mathrm{R} \$ 110,43$ & $-57 \%$ \\
\hline Topamax 25mg & & $\mathrm{R} \$ 148,32$ & $\mathrm{R} \$ 203,73$ & $-27 \%$ \\
\hline Topiramato 100mg & \multirow{2}{*}{$\begin{array}{l}60 \text { Comprimidos } \\
\text { Revestidos }\end{array}$} & $\mathrm{R} \$ 186,58$ & $\mathrm{R} \$ 389,78$ & $-52 \%$ \\
\hline Topamax 100mg & & $\mathrm{R} \$ 422,99$ & $\mathrm{R} \$ 670,90$ & $-37 \%$ \\
\hline
\end{tabular}


Tabela 1. Medicamentos com menores e maiores diferenças médias de preços em relação ao PMC.

\begin{tabular}{|c|c|c|}
\hline Medicamentos analisados & $\begin{array}{c}\text { Tipo } \\
\text { (quantidade) }\end{array}$ & $\begin{array}{c}\text { Diferença média percentual } \\
\text { de preços das concentrações } \\
\text { observadas }\end{array}$ \\
\hline Divalproato de Sódio (125 mg) & Genérico (1) & $-7 \%$ \\
\hline $\begin{array}{l}\text { Cosopt }(2 \% / 0,5 \%) \text {; Polaramine }(0,4 \mathrm{mg} / \mathrm{ml}) \text {; Tegretol } \\
(20 \mathrm{mg} / \mathrm{ml}) ; \text { Zinnat }(250 \mathrm{mg}) ; \text { Zyprexa }(10 \mathrm{mg}, 2,5 \mathrm{mg} \text { e } 5 \mathrm{mg})\end{array}$ & Referência (5) & $-8 \%$ \\
\hline $\begin{array}{l}\text { Flagyl (250mg); Lexapro }(20 \mathrm{mg} / \mathrm{ml}) \text {; Polaramine }(2 \mathrm{mg}) \text {; } \\
\text { Tylex (30mg) }\end{array}$ & Referência (4) & $-9 \%$ \\
\hline Polaramine (10mg) & Referência (1) & $-10 \%$ \\
\hline $\begin{array}{l}\text { Cloridrato de Duloxetina (30mg); Gabapentina (300mg); } \\
\text { Topiramato (50mg) }\end{array}$ & Genérico (3) & $-60 \%$ \\
\hline Prozac $(20 \mathrm{mg})$ & Referência (1) & $-62 \%$ \\
\hline Aciclovir (200mg); Dicloridrato de Pramipexol (1mg) & Genérico (2) & $-63 \%$ \\
\hline $\begin{array}{l}\text { Cloridrato de Fluoxetina (20mg); Cloridrato de Sertralina } \\
(50 \mathrm{mg}) \text {; Olanzapina }(2,5 \mathrm{mg})\end{array}$ & Genérico (3) & $-65 \%$ \\
\hline Olanzapina (5mg); Cymbalta (30mg) & $\begin{array}{l}\text { Genérico (1); } \\
\text { Referência (1) }\end{array}$ & $-70 \%$ \\
\hline Bissulfato de Clopidogrel (75mg); Cymbalta (60mg) & $\begin{array}{l}\text { Genérico (1); } \\
\text { Referência (1) }\end{array}$ & $-72 \%$ \\
\hline $\begin{array}{l}\text { Oxalato de Escitalopram (10mg, } 15 \mathrm{mg}, 20 \mathrm{mg}, 10 \mathrm{mg} \text { e } 20 \mathrm{mg} / \\
\mathrm{ml} \text { ) }\end{array}$ & Genérico (1) & $-75 \%,-68 \%,-69 \%,-83 \%$ e $-75 \%$ \\
\hline
\end{tabular}

\section{Discussão}

Neste artigo, estudou-se apenas um dos problemas da regulação de preços apontados pela literatura, o da distorção dos preços praticados em relação ao PMC. As evidências observadas pela coleta de preços praticados confirmam a presença desse problema na regulação brasileira alargando a percepção já manifestada pelo artigo de Miziara e Coutinho9. O argumento principal para explicar o distanciamento maior para o preço dos genéricos pode ser a quantidade de descontos praticados pelos produtores desses medicamentos para incentivar a comercialização de seus produtos, como identificado por Palmeira Filho ${ }^{25}$.

Como foi possível observar neste estudo, as diferenças médias percentuais entre preços praticados e PMCs foram bastante expressivas, sobretudo no que diz respeito aos medicamentos genéricos, em que cerca de $72 \%$ destes medicamentos tenderam a praticar diferenças que estavam mais de $40 \%$ abaixo do PMC que lhes é imposto. Com isso, pode-se inferir que o teto de preços imposto pela CMED aos medicamentos desse segmento no mercado brasileiro parece ser tão alto que acaba prejudicando o objetivo da própria regulação para os genéricos e, nesse caso, a concorrência parece ser o principal fator de estímulo à redução de preços ${ }^{21}$.

Em 2012, o relatório do Acórdão 3.016 do Tribunal de Contas da União (TCU) ${ }^{26}$ já havia recomendado ao Ministério da Saúde revisar e corrigir o modelo regulatório previsto na Lei 10.742/03, de forma a desvincular os reajustes da inflação. Após constatarem que $86 \%$ dos medicamentos de uma amostra de fármacos com maior faturamento apresentavam preço acima da média internacional, sendo $46 \%$ com maior preço no Brasil, recomendou também a revisão periódica dos preços a partir de critérios como comparação internacional, variação cambial e custos dos diferentes tratamentos. $\mathrm{O} \$ 9^{\circ}$ do art. $4^{\circ}$ da Lei 10.742/03 declara que, excepcionalmente, poderá ser determinado um reajuste negativo de preços em 31 de agosto de 2003. Não sendo prevista, porém, a redução de preços vigentes pela fórmula de reajuste.

O Acórdão deu margem a uma consulta pública, que culminou na mudança de parâmetros para cálculo do reajuste de preços, mostrando que algum grau de alteração na forma de cálculo dos parâmetros é viável, ainda que vigore a lei atual ${ }^{8}$. Isso ficou claro com a publicação da Medida Provisória (MP) 754/1627. A CMED passou a contar com a possibilidade de determinar 
o reajuste para baixo do preço vigente ${ }^{9,28}$. Porém, essa MP foi encerrada no mesmo ano, após uma carta de exposição de motivos ${ }^{29}$ informando que o ajuste negativo de preços deve ocorrer, excepcionalmente, quando observadas distorções de preços, de modo a atacar pontualmente as distorções detectadas, proporcionar equilíbrio de condições e gerar maior competitividade no mercado.

Outro aspecto que pode explicar os resultados observados é que as dinâmicas de mercado para medicamentos genéricos e de referência ocorrem de formas diferentes. Para os medicamentos genéricos, a concorrência tende a ocorrer via preços ou descontos, enquanto para os medicamentos de referência predomina a concorrência por diferenciação de produtos distinguidos por patentes e marcas ${ }^{2,30}$. Sendo assim, a concorrência entre os medicamentos de referência e genéricos, mesmo após o fim da vigência das patentes, ocorre em condições diferenciadas. A lealdade à marca garante aos medicamentos de referência uma demanda inelástica ao preço; e a percepção do genérico como intercambiável entre vários genéricos e o de referência torna a demanda elástica ao preço ${ }^{30}$.

Esta dinâmica de mercado pode ser um dos motivos que levam os genéricos a se distanciarem mais do PMC que os medicamentos de referência. Esse ponto foi corroborado por Dantas e Mendonça ${ }^{31}$ ao mostrarem que a política de diminuição de preços via introdução de genéricos é uma forma indireta de controlar os preços, uma vez que atua sobre a concorrência e não sobre as características que definem os preços diretamente. $\mathrm{O}$ modelo adotado pelos autores sugeriu que pode estar ocorrendo uma forma de segmentação de mercado em função do aumento da distância entre os preços dos medicamentos genéricos e de referência ${ }^{31}$.

Como pôde ser observado nos resultados expostos, a determinação do PMC pela CMED parece fazer muito mais sentido para os medicamentos de referência, os quais vêm praticando preços bem próximos de seus PMCs. Miziara e Coutinho ${ }^{9}$ também observaram que as médias dos preços de medicamentos praticadas nas farmácias e drogarias estavam muito abaixo do PMC. Entre 2009 e 2012, 44 dos 129 preços praticados apresentaram variação superior a $20 \%$ entre a média de preços praticados e o PMC. Essa disparidade, segundo os autores, retrata os limites da regulação dos preços dos medicamentos feita no Brasil, que é incapaz de pressionar os preços de parte expressiva dos medicamentos a patamares inferiores àqueles determinados pela indústria. Além disso, como mostram Dias et al. ${ }^{8}$, os "descontos" médios praticados em relação aos preços-teto aumentaram de 34,69\% em 2012 para $41 \%$ em 2016 , ou seja, tem se observado uma maior tendência ao distanciamento com o passar dos anos. Como esta regulação nunca foi revisada, a ampliação do distanciamento entre preços praticados e PMC avança, podendo causar prejuízos aos consumidores.

Neste mesmo sentido, Monte ${ }^{32}$ aponta que o que tem se observado é uma regulação fragmentada e inefetiva, tendo em vista que os preços fixados são distorcidos, sendo inapta para impedir ajustes abusivos. Tais distorções permitem margens elevadas de comercialização mesmo após o fim do período de vigência da patente, quando era de se supor que o custo da pesquisa e desenvolvimento já havia sido pago. A conclusão a que Monte ${ }^{32}$ chega é que o modelo atual de regulação não garante a ampliação ao acesso de medicamentos, nem a redução dos preços, nem o interesse das empresas em aumentar a produtividade e reduzir custos. São fundamentais avaliações e monitoramentos das oscilações dos preços finais dos medicamentos, com comunicação com outros sistemas de dados e registros de preços, para que a CMED possa figurar realmente como reguladora. Para frear os preços abusivos impostos pela indústria farmacêutica o caminho, sem dúvida, é a transparência no estabelecimento dos preços e atuação conjunta dos órgãos estatais ${ }^{32}$.

Como já colocado por Miziara e Coutinho9, os principais motivos para que seja observada essa considerável diferença entre o PMC e os preços praticados são a ausência de monitoramento efetivo dos preços dos medicamentos nos pontos de venda pela CMED e a falta de previsão legal da possibilidade de redução dos preços regulados dos medicamentos. Em 2017, em meio a polêmicas, a CMED chegou a emitir a Orientação Interpretativa $n^{\circ} 2$, esclarecendo que a Tabela CMED é tão somente uma tabela de teto de preços ${ }^{8}$. Porém, não faz sentido acreditar que uma regulação tem apenas como intuito servir como uma tabela que expõe preços máximos, mas que não é capaz de pressionar os preços dos medicamentos de forma efetiva para baixo, sem exercer qualquer tipo de pressão sobre a indústria farmacêutica. Desse modo, apesar da Tabela CMED ser apenas uma simples tabela de teto de preços, esta tem deixado de desempenhar a sua função principal, a de pressionar os preços dos medicamentos no Brasil, se tornando inócua em diversos sentidos.

Esse entendimento também é expresso por Maluf $^{f^{3}}$, que afirma que a CMED é um importan- 
te órgão regulador e não pode se restringir à mera edição de tabelas de preços. Maluf ${ }^{33}$ afirma que a edição de normas inadequadas, ou a interferência inoportuna, além de dificultar o acesso aos medicamentos não resolve a questão da sua falta, agravando ainda mais o problema, acirrando as próprias desigualdades e falhas do mercado, além do mais, afugenta os agentes econômicos levando consigo os investimentos e deixa a população mais carente de medicamentos, concluindo que a regulação malfeita é ainda pior que a ausência de regulação.

O modelo que determina o teto de preços no Brasil é utilizado para medicamentos de forma geral, seja este um genérico ou um de referência. O reajuste de preços, entretanto, diferencia-se pelo grau de concentração em que esses medicamentos atuam. Todavia, foi possível notar que os medicamentos de referência têm mantido seus preços mais próximos ao teto estabelecido que os genéricos, os quais tendem a descolar muito mais o seu preço praticado do PMC. Na Noruega, como mostram Brekke et al. ${ }^{34}$, quando vigorava o modelo de teto de preços, compulsório apenas para o medicamento de referência, observaram que o preço deste medicamento tendia a flutuar próximo ao teto estabelecido, enquanto o preço do genérico tendia a se reduzir bastante. Desta maneira, a adoção do modelo de teto de preços também para os genéricos, como a que vigora no Brasil, pode ser um dos fatores que tem levado a não efetividade da regulação atual.

Como aponta Delgado ${ }^{35}$, a regulação econômica deve adotar novas estratégias para corrigir ou ajustar o custo do medicamento ao consumidor final que não tem ou tem pouco acesso a medicamentos considerados essenciais diante de um mercado em que a invenção e o desenvolvimento de novos medicamentos têm mais valia. $\mathrm{O}$ autor sugere que as condições da concorrência, nesse mercado, tornam desafiador o acesso a medicamentos pela população, dificultando atingir aquilo que se espera da boa regulação, ou seja, maximizar o bem-estar social e o bem-estar do consumidor, sem prejudicar a cadeia produtiva farmacêutica e vice-versa.

Recentemente, em meio à pandemia da $\mathrm{CO}$ VID-19, apesar de se ter sido adiado o reajuste de preços dos medicamentos por dois meses, alguns especialistas observaram que isto pouco resolveria o problema de aumento de preços dos medicamentos no mercado. Isto ocorreria principalmente porque, como comentado neste artigo, os fabricantes têm uma vasta margem que os permite aumentar os preços dos medicamentos dentro do atual limite legal estabelecido pela CMED. $O$ reajuste não tende a incidir diretamente sobre os preços dos medicamentos, mas sim sobre o teto de preços. Como esse teto é muito elevado, na prática ele não limita os preços desses produtos, como afirmou Ana Navarrete do Instituto Brasileiro de Defesa do Consumidor ${ }^{36}$.

Após os dois meses de suspensão do reajuste de preços dos medicamentos, o Governo Federal chegou a autorizar o reajuste nos preços de medicamentos para 2020 no dia $1^{\circ}$ de junho. Pela resolução da CMED publicada no Diário Oficial, o reajuste máximo permitido para 2020 seria aplicado em três faixas, de 5,21\%, 4,22\% e $3,23 \%$, a depender do tipo de medicamento. O teto do aumento autorizado para 2020 é superior ao do ano anterior, que foi de $4,33 \%$. Porém, no dia 2 de junho de 2020, o Senado aprovou um projeto de lei (PL 1.542/2020) que visa ampliar o período de suspensão do reajuste de preços dos medicamentos para 120 dias. A proposta ainda seria votada na Câmara dos Deputados ${ }^{37,38}$.

O que tem se observado na prática, apesar de não ter ocorrido o reajuste de preços dos medicamentos, são diversas denúncias de consumidores quanto à elevação do preço dos medicamentos durante a pandemia da Covid-1939-42. Porém, quando as denúncias de prática de preços abusivos chegam a ser analisadas pelo Programa de Proteção e Defesa do Consumidor (PROCON), observa-se que os preços estão dentro dos limites estabelecidos pela CMED. Isto confirma o que foi observado neste artigo, que, em determinados momentos, há uma enorme margem que os fabricantes podem utilizar para ampliar os preços dos medicamentos, que, em geral, estão muito abaixo do teto.

Dentre as limitações deste artigo, podemos citar: (1) a variedade de valores estabelecidos para o ICMS, que não foi levada em conta; (2) a utilização de dados de preços e disponibilidade dos medicamentos coletados apenas na internet, que podem diferir dos preços praticados nas lojas físicas; (3) a não distinção entre os preços praticados por estado; (4) a utilização de uma amostra pequena e de conveniência de medicamentos; (5) a utilização de uma amostra de preços referente a um único momento no tempo; (6) a não inclusão de farmácias independentes, utilizando apenas as grandes redes; e (7) a não inclusão de medicamentos similares. 


\section{Considerações finais}

A partir do estudo apresentado neste artigo, foi possível observar que tem havido um expressivo distanciamento entre os preços praticados e os PMCs estabelecidos para os medicamentos no Brasil. As diferenças entre preços praticados e PMCs foram bastante expressivas, sobretudo no que diz respeito aos genéricos, em que cerca de $72 \%$ destes medicamentos tenderam a praticar diferenças que estavam mais de $40 \%$ abaixo do PMC. Enquanto cerca de $88 \%$ dos medicamentos de referência tendia a praticar diferenças de preços que estavam menos de $40 \%$ abaixo do PMC.

Esse maior distanciamento entre preços praticados e PMCs permite que, em momentos de crise, como no caso da pandemia da COVID-19, as empresas farmacêuticas possam ampliar o preço de seus produtos no mercado, sem desrespeitar a regulação vigente. Ressalta-se que isto pode se dar não somente em momentos de crise, mas que a crise reforça o espaço que essas empresas possuem. Por este motivo, é importante que haja avaliações periódicas dos preços praticados no mercado e um realinhamento dos tetos de preços estabelecidos, principalmente para os medicamentos genéricos para que não sejam praticados preços mais elevados do que os que de fato deveriam prevalecer.

Em conclusão, pode-se afirmar que o teto de preços imposto aos medicamentos tem feito mais sentido para os medicamentos de referência do que para os genéricos. Por este motivo, espera-se que os resultados deste artigo sejam capazes de alertar sobre a necessidade de avaliações aprofundadas sobre o método de estabelecimento de teto do preço dos medicamentos no Brasil, complementando as evidências aqui apontadas, que indicam a necessidade de uma revisão da regulação atualmente adotada.

\section{Colaboradores}

Concepção e delineamento: CMA Souza, J Paranhos e L Hasenclever. Análise e interpretação dos dados: CMA Souza. Redação do artigo: CMA Souza. Revisão crítica: J Paranhos e L Hasenclever. Aprovação da versão a ser publicada: CMA Souza, J Paranhos e L Hasenclever. 


\section{Referências}

1. Kornis GEM, Braga MH, Fagundes M, De Paula PAB. A regulação em saúde no Brasil: um breve exame das décadas de 1999 a 2008. Physis 2011; 21(3):1077-1101.

2. Nishijima M, Biasoto Jr G, Lagroteria E. A competição no mercado farmacêutico brasileiro após uma década de medicamentos genéricos: uma análise de rivalidade em um mercado regulado. Economia e Sociedade 2014; 23(1):155-186.

3. Brasil. Lei no 10.742 de 6 de outubro de 2003. Define normas de regulação para o setor farmacêutico, cria a Câmara de Regulação do Mercado de Medicamentos - CMED e altera a Lei no 6.360 de 23 de setembro de 1976, e dá outras providências. Diário Oficial da União 2003; 7 out.

4. Câmara de Regulação de Medicamentos (CMED). Resolução no 1 , de 26 de março de 2019. Dispõe sobre a forma de definição do Preço Fabricante (PF) e do Preço Máximo ao Consumidor (PMC) dos medicamentos em 31 de março de 2019, estabelece a forma de apresentação do Relatório de Comercialização à Câmara de Regulação do Mercado de Medicamentos - CMED, disciplina a publicidade dos preços dos produtos farmacêuticos e define as margens de comercialização para esses produtos. Diário Oficial da União 2019; 29 mar.

5. Brasil. Lei n. 9.787. Altera a Lei n. 6.360, de 23 de setembro de 1976, que dispõe sobre a vigilância sanitária, estabelece o medicamento genérico, dispõe sobre a utilização de nomes genéricos em produtos farmacêuticos e dá outras providências. Diário Oficial da União 1999; 11 fev.

6. Agência Nacional de Vigilância Sanitária (Anvisa). Farmacopeia Brasileira. 6a ed., vol. I. Brasília: Anvisa; 2019. [acessado 2020 jul 25]. Disponível em: http:// portal.anvisa.gov.br/documents/33832/259143/ Volume+I+Pronto.pdf/4ff0dfe 8-8a1d-46b9-84f77 fa9673elee1

7. Câmara de Regulação de Medicamentos (CMED). Resolução no 2, de 5 de março de 2004. Aprova os critérios para definição de preços de produtos novos e novas apresentações de que trata o art. $7^{\circ}$ da Lei n ${ }^{\circ}$ 10.742, de 6 de outubro de 2003. Diário Oficial da União 2004b; 5 mai.

8. Dias LLS, Santos MAB, Pinto CBS. Regulação contemporânea de preços de medicamentos no Brasil - uma análise crítica. Saude Debate 2019; 43(121):543-558.

9. Miziara NM, Coutinho DR. Problemas na política regulatória do mercado de medicamentos. Rev Saude Publica 2015; 49:1-6.

10. Associação Brasileira de Redes de Farmácias e Drogarias (ABRAFARMA). [acessado 2019 jan 20]. Disponível em: https://www.abrafarma.com.br/

11. Droga Raia [acessado 2019 out 21]. Disponível em: http://drogaraia.com.br/nossa-historia

12. Drogasil [acessado 2019 out 21]. Disponível em: https://www.drogasil.com.br/nossa-historia

13. Drogarias Pacheco [acessado 2019 out 21]. Disponível em: https://www.drogariaspacheco.com.br/institucional/drogarias-pacheco

14. Drogaria São Paulo [acessado 2019 out 21]. Disponível em: https://www.drogariasaopaulo.com.br/institucional/drogarias-sao-paulo
15. Panvel [acessado 2019 out 21]. Disponível em: https:// www.panvel.com/panvel/institucional.do?secao=quemSomos

16. Pague Menos [acessado 2019 out 21]. Disponível em: http://portal.paguemenos.com.br/portal/empresa\#0

17. Drogaria Araujo [acessado 2019 out 21]. Disponível em: https://www.araujo.com.br/conteudo-empresa

18. Farmácias Nissei [acessado 2019 out 21]. Disponível em: https://www.farmaciasnissei.com.br/sobre-nos

19. Drogaria Venancio [acessado 2019 out 21]. Disponível em: https://www.drogariavenancio.com.br/institucional/sobre

20. Drogal [acessado 2019 out 21]. Disponível em: https:// www.drogal.com.br/quem-somos/s

21. Souza CMA. A regulação do preço dos medicamentos genéricos no Brasil [dissertação]. Rio de Janeiro: Universidade Federal do Rio de Janeiro; 2020.

22. Câmara de Regulação de Medicamentos (CMED). Preços máximos de medicamentos por princípio ativo, atualizada em 01/07/2019 [acessado 2019 ago 28]. Disponível em: http://portal.anvisa.gov.br/documents /374947/2829072/LISTA+CONFORMIDADE_201907-01.pdf/d3cffaba-8cc5-49b2-a3c4-b 0230686a975

23. Agência Nacional de Vigilância Sanitária (Anvisa). Medicamentos similares intercambiáveis [acessado $2021 \mathrm{fev}$ 18]. Disponível em: http://antigo.anvisa.gov. $\mathrm{br} /$ medicamentos-similares

24. Agência Nacional de Vigilância Sanitária (Anvisa). Lista de registros de medicamentos genéricos, atualizada em 05/08/2019 [acessado 2020 out 22]. Disponível em: https://www.gov.br/anvisa/pt-br/assuntos/ medicamentos/genericos/estatisticas/arquivos/6457json-file-1

25. Palmeira Filho PL. Catch-up da indústria farmacêutica nacional e financiamento à inovação: o caso da atuação do BNDES através do Profarma [tese]. Rio de Janeiro: Universidade Federal do Rio de Janeiro; 2013.

26. Tribunal de Contas da União (TCU). Acórdão 3016/2012 - plenário. Processo 034.197/2011-7 [acessado $2021 \mathrm{fev} 18$ ]. Disponível em: https://pesquisa. apps.tcu.gov.br/\#/documento/acordao-completo/ ${ }^{*} /$ KEY\%253AACORDAO-COMPLETO-1250289/ DTRELEVANCIA\%2520desc/0/sinonimos\%253Dfalse

27. Brasil. Medida Provisória no 754, de 19 de dezembro de 2016. Diário Oficial da União 2016; 20 dez.

28. Sarai L, Pscheidt KR. Regulação de preços de medicamentos: o Estado está no caminho certo? Revista de Direito Econômico e Socioambiental 2018; 9(2):140172.

29. Brasil. E.M.I. no 00052/2016/MS/CC-PR/MDIC/MJC. Brasília, 12 de dezembro de 2016. [acessado $2021 \mathrm{fev}$ 18]. Disponível em: http://www.planalto.gov.br/ccivil_03/_Ato2015-2018/2016/Exm/Exm-MP-754-16. pdf

30. Hasenclever L, Fialho B, Klein H, Zaire C. Economia Industrial de Empresas Farmacêuticas. Rio de Janeiro: E-papers; 2010.

31. Dantas AT, Mendonça PAS. Impactos concorrenciais da entrada dos medicamentos genéricos no mercado farmacêutico brasileiro de 2003 a 2007. Análise Econômica 2014; 32(58):101-124. 
32. Monte RG. Regulação jurídica e econômica do mercado de medicamentos: fundamento, desafios e impactos regulatórios [dissertação]. Pernambuco: Universidade Federal de Pernambuco; 2019.

33. Maluf E. O controle de preço de medicamentos. Revista de Direito Sanitário 2011; 12(1):67-84.

34. Brekke KR, Grasdal AL, Holmas TH. Regulation and pricing of pharmaceuticals: reference pricing or pricecap regulation? Eur Econ Rev 2009; 53:170-185.

35. Delgado JS. Medicamentos: o preço da saúde. Revista de Direito Setorial e Regulatório 2015; 2(1):269-288.

36. Junqueira D. Coronavírus: remédios devem subir, mesmo após governo adiar reajuste. Repórter Brasil; 2020 abr 03 [acessado 2020 jun 16]. Disponível em: https://economia.uol.com.br/noticias/redacao/ 2020/04/03/coronavirus-remedios-devem-subir-mesmo-apos-governo-adiar-reajuste.htm

37. Após suspensão, governo autoriza reajuste de até 5,2\% nos preços dos medicamentos. Estadão; 2020 jun 02 [acessado 2020 jun 16]. Disponível em: https:// revistapegn.globo.com/Banco-de-ideias/Saude/noticia/2020/06/pegn-apos-suspensao-governo-autoriza -reajuste-de-ate-52-nos-precos-dos-medicamentos. html

38. Aprovada suspensão de reajuste de remédios e de planos de saúde. Agência Senado; 2020 jun 02. [acessado 2020 jun 16]. Disponível em: https://www12.senado. leg.br/noticias/materias/2020/06/02/aprovada-suspensao-de-reajuste-de-remedios-e-de-planos-desaude

39. Variação no preço de medicamentos pode chegar a 200\%, em Goiânia. Globoplay; 2020 maio 1 [acessado 2020 jun 16]. Disponível em: https://globoplay.globo. $\mathrm{com} / \mathrm{v} / 8525999 /$

40. Com alta no preço de Azitromicina, Cloroquina e Tamiflu, Procon notifica farmácias de Manaus. G1 AM; 2020 maio 19 [acessado 2020 jun 16]. Disponível em: https:/gl.globo.com/am/amazonas/ noticia/2020/05/19/com-alta-no-preco-de-azitromicina-cloroquina-e-tamiflu-procon-notifica-farmarcias-de-manaus.ghtml

41. Procon realiza fiscalização em farmácias e drogarias de Belém. Globoplay; 2020 maio 22 [acessado 2020 jun 16]. Disponível em: https://globoplay.globo. $\mathrm{com} / \mathrm{v} / 8573264 /$

42. Escassez de medicamentos e preços altos preocupam consumidor. Globoplay; 2020 maio 01 [acessado 2020 jun 16]. Disponível em: https://globoplay.globo. $\mathrm{com} / \mathrm{v} / 8526229 /$

Artigo apresentado em 02/08/2020

Aprovado em 05/03/2021

Versão final apresentada em 07/03/2021

Editores-chefes: Romeu Gomes, Antônio Augusto Moura da Silva 